\title{
Quantitative Correlation Between Barrel-Field Size and the Sensory Innervation of the Whiskerpad: A Comparative Study in Six Strains of Mice Bred for Different Patterns of Mystacial Vibrissae
}

\author{
Egbert Welker and Hendrik Van der Loos \\ Institute of Anatomy, University of Lausanne, 1005 Lausanne, Switzerland
}

In mice from 6 strains bred for different patterns of mystacial vibrissae, we studied the consequences of the presence of supernumerary whiskers for the sensory innervation of the vibrissal follicles and their cortical representation in the barrel field. The parameters were number of axons innervating individual vibrissal follicles, tangential area of individual barrels, and thickness of the layers in the barrel cortex. These parameters are highly constant for animals within a strain but may differ greatly between strains. For all strains, the innervation of a follicle depends on its position on the whiskerpad, the highest innervation density being at the posterolateral corner. This matches the wave of development that travels over this part of the face during embryogenesis. Although large differences exist between strains in the number of axons innervating the whiskerpad, the relative number of axons innervating the "standard" follicles of 1 row is remarkably constant. The thickness of the barrel cortex increases from posteromedial to anterolateral for all strains. This increase is due to variations in thickness of the cortical output layers (II and III, V and VI).

For individual barrel-follicle pairs, we calculated the ratio between cortical barrel area and axon number. The major findings were that (1) supernumerary follicles are innervated and, given a threshold number of axons, represented by barrels; (2) barrel area per peripheral axon differs between follicles within a row and is highest for the supernumerary elements; and (3) for each strain there is a direct, linear correlation between axon number and barrel size, which differs significantly among certain, but not all, strains. The data allowed us tentatively to define some of the factors that play a role in the formation of brain maps and pointed to the existence of major genetic differences between mouse strains with respect to these factors.

Since 1977 we have selectively bred a number of mouse strains that differ in number and pattern of mystacial vibrissae, starting with a selection made from a large population of albino mice from an outbred ICR stock (Van der Loos et al., 1984). Thirteen bilaterally symmetric patterns were obtained, and the "improvement" of the strains in question has been the subject of recent reports (Van der Loos and Welker, 1985; Van der Loos et al., 1986). We proved that the patterns, both standard and "enriched," are genetically determined.

Six strains from that group have been selected for the present

Received Oct. 15, 1985; revised Mar. 27, 1986; accepted May 6, 1986.

Among the many people who helped with various aspects of this work, we thank particularly K. Van der Saag, G. and M. Rumo, J. Dubach, A. J. R. Van der Loos, A. Keller, N. Schmidt, N. Van der Loos, M. C. Cruz, E. Desponds, S. Daldoss, D. Stücki, R. Kraftsik, A. Cobas and P. G. H. Clarke. Financial support was provided by Swiss National Science Foundation grants 3.238 and 3.158.

Correspondence should be addressed to Egbert Welker, Institute of Anatomy, University of Lausanne, Rue du Bugnon 9, 1005 Lausanne, Switzerland.

Copyright (C) 1986 Society for Neuroscience $0270-6474 / 86 / 113355-19 \$ 02.00 / 0$ analysis. One strain shows the standard pattern, the common denominator for all 6 strains. The 5 other strains each manifested supernumerary whiskers (SWs) and corresponding supernumerary barrels (SBs) - a different set for each strain. For the supernumerary elements (SEs), a deoxyglucose study (Welker et al., 1985; see Melzer et al., 1985, for the procedure) showed that the SEs are parts of functionally operative chains. We deal with mice that are normal in all respects except for the presence of SEs.

The ensemble of barrels forms the barrel field (T. A. Woolsey and Van der Loos, 1970); the part that forms the representation of the large mystacial vibrissae has been called the "posteromedial barrel subfield" but is here referred to simply as the barrel field.

Enriched peripheries have been shown to lead to domains in the CNS that are larger and/or contain more neurons for a variety of animals: frogs with supernumerary limbs (Hamburger, 1939) and eyes (Constantine-Paton and Law, 1978), chick embryos with supernumerary legs (Hollyday and Hamburger, 1976), Drosophilae with supernumerary bristles (Ghysen, 1980), and mice with implanted supernumerary whiskerpads (Andrés and Van der Loos, 1985). However, in these experimentally enriched conditions, measuring and counting of constituent parts have never been done on the individual elements of a topologically organized array, perhaps because of the less "punctiform" arrangement, in most of these animals, of the 2 ends of the pathway involved.

In a previous study on the mouse somatosensory system (Welker and Van der Loos, 1986), we introduced the ratio "cortical area per peripheral axon" in order to quantify the relationship between follicular innervation and barrel-field area. This ratio does not imply that we assume a particular peripheral sensory nerve fiber signals to 1 column of cortical tissue exclusively in a given area. That study demonstrated that this ratio in normal animals differed from that in animals whose barrel fields had been altered by (1) lesioning the whiskerpads of neonates or (2) genetically creating SWs. Here, we use the same concept but now compare, within each strain, the area of individual barrels with the innervation of the corresponding follicles. Not only are there significant differences among the strains, but within a strain the SEs appear to follow different rules in the establishment of that ratio than do the elements of the standard set.

In the first study of somatosensory maps, C. N. Woolsey et al. (1942) described the principle of cortical magnification, which was later demonstrated for the visual (Daniel and Whitteridge, 1961) and auditory (Suga and Jen, 1976; Suga et al., 1975) systems. In a study (Lee and Woolsey, 1975) on the mouse, the number of axons innervating each of the 6 tallest follicles of the $C$ row was compared with the number of neurons in the corresponding barrels, and a linear relationship was found between the 2 sets of values. The authors proposed that a similar rela- 
Table 1. Description of data with respect to mice used in this study

\begin{tabular}{|c|c|c|c|c|c|c|}
\hline Strain & $N O R$ & $A / A$ & $H / H$ & $M A P$ & $M C P$ & $M / M$ \\
\hline No. of hemispheres and whiskerpads analyzed & 12 & 12 & 12 & 12 & 12 & 20 \\
\hline No. of animals from which hemispheres and whiskerpads were analyzed & 7 & 8 & 9 & 9 & 8 & 12 \\
\hline Males & 4 & 4 & 8 & 4 & 4 & 4 \\
\hline Females & 3 & 4 & 1 & 5 & 4 & 8 \\
\hline Generation(s) from which animals were taken & 17,21 & 16,19 & $15,20,21$ & 13 & $11,12,20$ & $8,10,12$ \\
\hline No. of hemispheres analyzed for cortical thickness & 6 & 6 & 6 & 6 & 6 & 6 \\
\hline No. of animals from which hemispheres were analyzed & 6 & 5 & 6 & 5 & 4 & 4 \\
\hline Males & 4 & 4 & 5 & 2 & 4 & 2 \\
\hline Females & 2 & 1 & 1 & 3 & - & 2 \\
\hline Generation(s) from which animals were taken & 17,21 & 19 & 20,21 & 13 & 20 & 12 \\
\hline Mean body weight of animals at postnatal day $60(\mathrm{gm})$; (SDs in parentheses) & $\begin{array}{c}29.0 \\
(4.5)\end{array}$ & $\begin{array}{l}36.7 \\
(3.1)\end{array}$ & $\begin{array}{c}38.0 \\
(2.8)\end{array}$ & $\begin{array}{l}29.5 \\
(5.5)\end{array}$ & $\begin{array}{l}33.0 \\
(4.4)\end{array}$ & $\begin{array}{l}31.3 \\
(3.8)\end{array}$ \\
\hline
\end{tabular}

tionship exists between innervation of a follicle and area of a barrel.

Our primary question was, How do the sensory periphery and the CNS cope with the presence of SEs? In an "cnriched" animal, are the total number of axons and the total cortical space allotted to infraorbital nerve and barrel field the same as in mice with only the standard set of follicles at their disposal, or does the Gasserian ganglion send more fibers to the muzzle, so as not to shortchange the standard follicles? And, with regard to the cortex, is the same total area parceled more finely when more barrels are present, or do SBs lead to a larger barrel field?

Several of our findings have previously been reported in abstracts (Welker and Van der Loos, 1983, 1984a, b).

\section{Materials and Methods}

The mice analyzed in this study were from 6 strains, all bred for bilaterally symmetric patterns of mystacial vibrissae. They originated from an outbred stock (ICR; Van der Loos et al., 1984) and were subsequently selectively inbred for a period of time before they were defined and named as strains (Van der Loos and Welker, 1985; Van der Loos et al., 1986). These strains were then separated and continued, as much as possible, hy brother-sister mating. Therefore, generation numbers used in Table 1, which contains a summary of the animals used, do not reflect the actual number of generations of inbreeding, except for strain $N O R$, which was defined as such from the very beginning; for the other strains, 6-10 generations would have to be added in order to give the actual number of generations of inbreeding.

The patterns of mystacial vibrissae for the 6 strains are illustrated in Figure 1; the strains are as follows:

NOR, bred for the absence of supernumerary whiskers (SWs). These mice possess the so-called "standard set" of whisker follicles, distributed over the whiskerpad in 5 horizontal rows of follicles (A, B, C, D, and E, A being dorsalmost) and in 1 vertical row of 4 follicles $(\alpha, \beta, \gamma$, and $\delta$ ) that straddle the most caudal follicles of the 5 horizontal rows.

$A / A$, bred for the bilateral presence of an $\mathrm{SW}$ at the rostral end of the A row, called A5.

$H / H$, bred for the bilateral presence of $\mathrm{A} 5$ and $\mathrm{B} 5$, the latter being the fifth element of the $B$ row.

$M A P$, bred for a maximal number of SWs in the strip of skin just medial to the A row, called the $\mathrm{A}^{\prime}$ whisker. In most cases, A5 is present as well, B5 less frequently.

$M C P$, bred for maximal numbers of SWs $\left(\mathrm{C}^{\prime}\right)$ in the strip of skin between the $\mathrm{B}$ and $\mathrm{C}$ rows. Most $M C P$ mice possess $\mathrm{A} 5$ and $\mathrm{B} 5$ whiskers as well as SWs among the straddlers.

$M / M$, bred for maximal numbers of SWs, irrespective of site; in mice of this strain, A5, B5, and A's and C's are the most frequently occurring SWs; more recent generations, however, have SWs between the A and $B$ rows (called B' whiskers), as well as among the straddlers. Among the animals studied, there was only 1 that had a $B^{\prime}$ whisker.

The $\mathrm{A}^{\prime}, \mathrm{B}^{\prime}$, and $\mathrm{C}^{\prime}$ whiskers are numbered according to their relative position with respect to the follicles of the $A, B$, and $C$ rows, respectively. The corresponding barrels in the barrel field, situated in topologically equivalent sites, are named in a similar fashion.

\section{Histological procedures}

In a routine that held for all the mice born into our colony, newborns were checked for the presence of SWs at PO (the first day of postnatal life). For details concerning animal maintenance, see Van der Loos et al. (1986). Animals selected for analysis were separated from the colony. At $60 \mathrm{~d}$ of age, they were anesthetized with pentobarbital (i.p.), weighed, and transcardially perfused with $10 \%$ neutralized formalin in $0.9 \% \mathrm{NaCl}$. After perfusion, the whiskerpads were removed and the skull was opened. Whiskerpads and heads were kept in the same solution overnight. The brain was removed from the skull. Whiskerpads and brains were postfixed for at least 1 week. Whiskerpads were immersed in $20 \%$ sucrose and cut in a cryostat tangentially to the skin surface at $15 \mu \mathrm{m}$; alternate sections were stained for myelin, using a modification of Lillie's method (M. C. Cruz, E. Welker, B. Ghavami, and H. Van der Loos, unpublished observations) or according to a reduced-silver method (Cruz et al., 1984). Brains were dehydrated, bisected in the midsagittal plane in a 95\% ethanol solution, and embedded in celloidin. 'The blocks were oriented so they could be cut at $40 \mu \mathrm{m}$ tangentially to the pia above the barrel field (Rice and Anders, 1977; T. A. Woolsey and Van der Loos, 1970). The sections were stained with methylene blue. Hemispheres used for cortical thickness measurements were processed in an identical fashion, except that they were cut coronally, perpendicular to a plane arrived at by tilting by $10^{\circ}$-rostral end up-a "horizontal" plane defined by 2 notches on the dorsal aspect of the cerebral cortex (one between it and the olfactory bulb, the other between it and the superior colliculus). All brains were cut serially, and all sections through the pertinent part of the parietal cortex were processed.

\section{Analysis: axon counts and area measurements}

In sections stained for myelin, axons were counted in the nerves innervating individual vibrissal follicles, using a compound microscope fitted with a $100 \times$ oil-immersion objective and a drawing tube. For each strain, the mean number of nerve fibers was calculated for each follicle. The very small number of myelinated fibers entering the follicles via the conus nerves (Andrés, 1966; Vincent, 1913) was not taken into account. The areas of individual barrels were measured from camera lucida reconstructions of the barrel field (made with a $10 \times$ objective) using a graphics tablet and a minicomputer. A barrel field could be drawn from 2-6 serial sections. By drawing a line through the center of the septa, septal domains were allocated to the barrels bordering them, so that the sum of the areas of the individual barrels equaled the total area of the barrel field. This routine was also followed in those cases where septa were unusually wide-for example, at sites corresponding with SWs that were not represented by barrels. For each strain, the mean area of each barrel was calculated.

Counts and measurements included the parts of the whiskerpad and barrel field that we defined as the standard set. This contained elements A1-4, B1-4, C1-6, D1-7, and E1-8 (Fig. 1, NOR). Moreover, the analysis included SEs: A5, B5, and the $A^{\prime}$ 's, B's, and $C^{\prime}$ s (Fig. 1). The straddling elements, including the SWs, were not taken into account because of the frequent difficulty in defining the caudal contour of their barrels. For each whiskerpad analyzed, the corresponding barrel field was measured. 

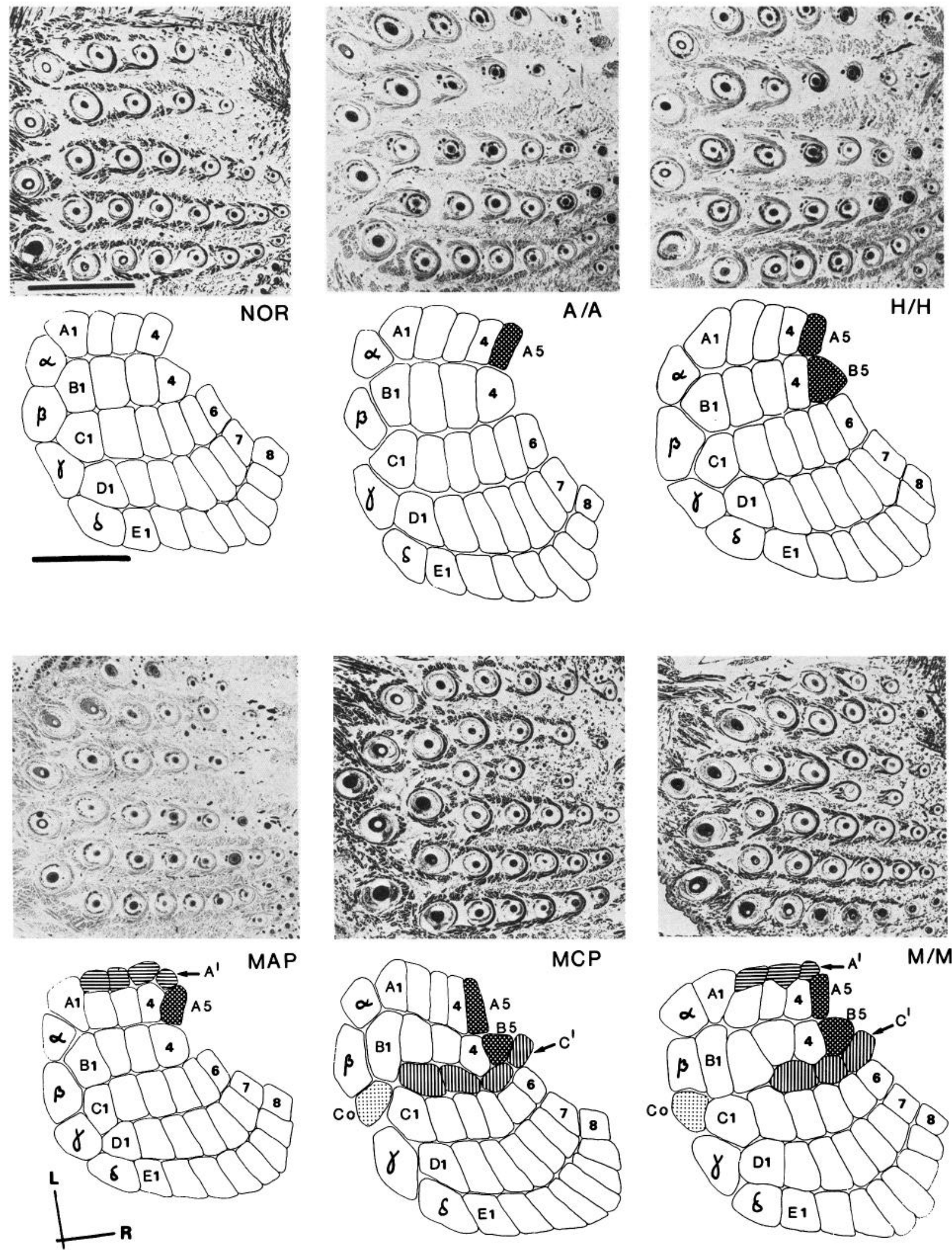

Figure 1. Photomicrographs of whiskerpads paired with drawings of corresponding barrel fields, showing the pattern of vibrissae and barrels for each of the 6 strains analyzed: NOR, $A / A, H / H, M A P, M C P$, and $M / M$. Sections of whiskerpads were stained for myelin $(A / A, H / H$, and $M A P)$ or by a reduced-silver method (NOR, $M C P$, and $M / M)$. The drawings are camera lucida reconstructions of barrel fields from Nissl-stained tangential sections through the parietal cortex. The orientation of barrel fields and whiskerpads is such that peripheral and central patterns can easily be compared. For whiskerpads, rostral is to the right, medial is $u p$; for barrel fields, see compass in bottom left corner ( $L$, lateral; $R$, rostral). Labeling of barrels is given for the first and last elements of rows that form the standard set; variously hatched barrels correspond to supernumerary whiskers, which are named according to the conventions introduced in the text. The straddling elements $(\alpha, \beta, \gamma$, and $\delta)$ are displayed, although they did not enter the present analysis (but see Fig. 12). Bar for whiskerpads (in NOR), $2 \mathrm{~mm}$; bar for barrel fields (in NOR), $500 \mu \mathrm{m}$. 

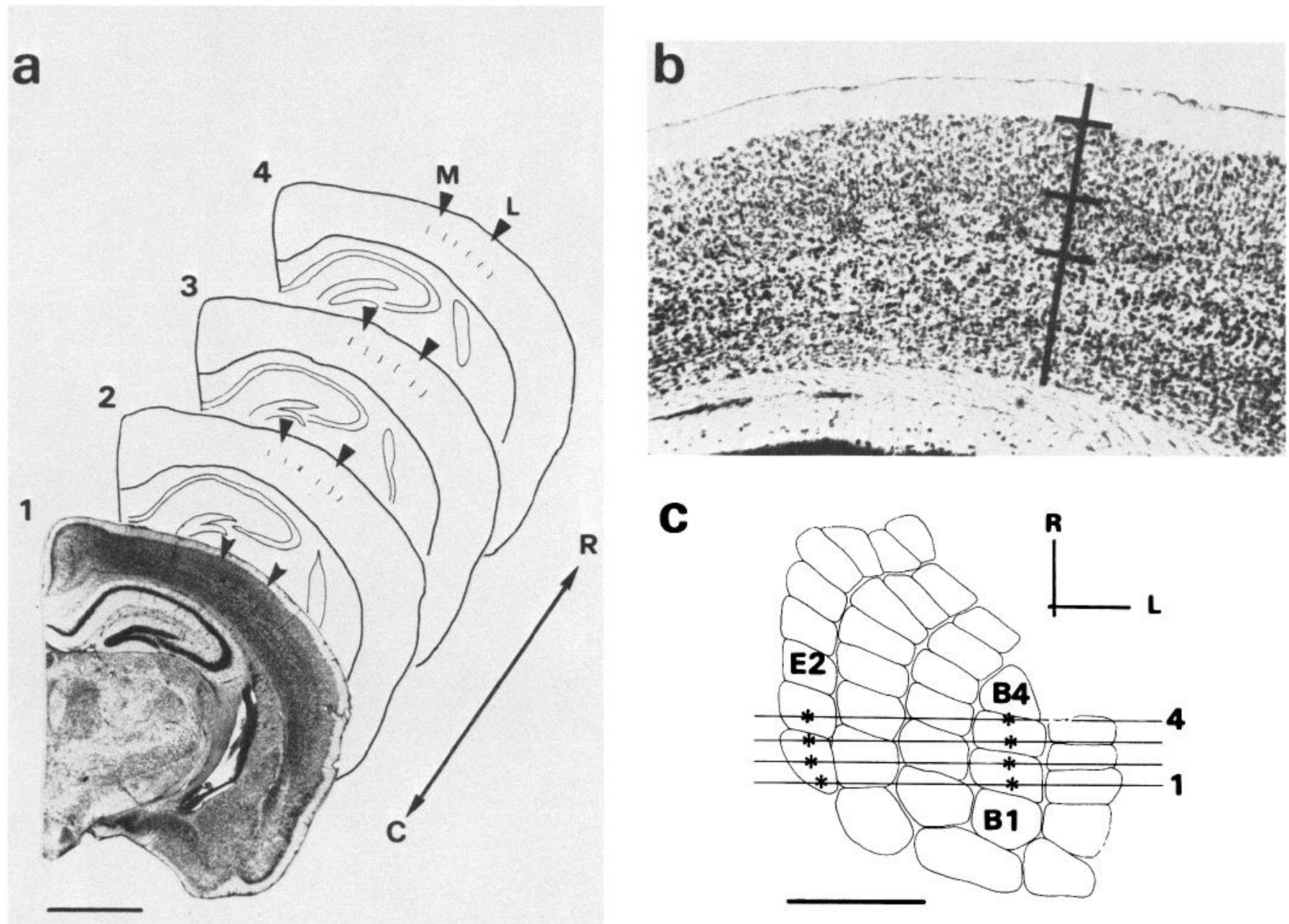

Figure 2. Explanation of analysis of cortical thickness made for mice from all 6 strains. $a$, Four coronal sections $(1-4)$ through the right hemisphere are displayed. In each section, measurements were performed at 2 sites: through the most medial barrel $(M)$ and through the fourth one from medial $(L)$. Photomicrograph is from a Nissl-stained section of 1 of the hemispheres analyzed; drawings of the other sections are displayed at the same magnification, indicated by bar $(1 \mathrm{~mm})$. Arrow shows the sequence of sections in a caudal-to-rostral (C-R) direction. $b$, Photomicrograph of a detail of barrel cortex shown in section 1 in $a$, taken at higher magnification and oriented in a similar way. Radial line crosses the whole cortex (thickness, $620 \mu \mathrm{m}$ ); lines perpendicular to it indicate borders between layers I and II, III and IV, and IV and V. $c$, Barrel-field drawing indicates approximately where measurements were taken (asterisks). Lines represent the sections shown in $a$. In compass, $R$ is rostral and $L$ is lateral. Bar, $500 \mu \mathrm{m}$.

\section{Analysis: cortical thickness measurements}

Cortical thickness measurements were made at sites in the cortex, as follows (Fig. 2): Coronal sections were scanned from caudal to rostral, and the first section clearly showing 5 adjacent barrels was taken for analysis. A drawing of the cortex on 1 side was made by camera lucida, using a $4 \times$ objective. Two points of measurement were chosen: through the hollow of the most medially situated barrel and through that of the fourth barrel, moving laterally (or of the fifth in the case of $M C P$ and $M / M$ animals). Thickness measurements were made with a $10 \times$ objective, superimposing a ruler, via the drawing tube, on the microscopic image of the cortex. These measurements were repeated in each second consecutive rostral section.

\section{Electron-microscopic procedures and analysis}

For the electron-microscopic study of follicular nerves, 60-d-old mice were anesthetized with pentobarbital (i.p.) and perfused with a mixture of paraformaldehyde $(1.5 \%)$ and glutaraldehyde $(1.5 \%)$ in $0.1 \mathrm{M}$ phosphate buffer. The heads were kept overnight in the same fixative at $4^{\circ} \mathrm{C}$, and individual follicles, together with the distal parts of the follicular nerves, were then carefully dissected out, dehydrated and block-stained with uranylacetate, and embedded in ERL-4206 (Spurr, 1969). Semithin and thin sections were cut from the nerve $\sim 10 \mu \mathrm{m}$ from the site where it was divided. Thin sections were stained with lead citrate and examined in a Philips 301 EM. For each nerve, 1 section was selected, and a montage, consisting of about 60 electron micrographs at $14,000 \times$, was made with the aid of a stage-position detection device (C. E. Leuenberger, H. Van der Loos, D. Anders, and N. König, unpublished observations) that allowed easy picture taking at preset intervals and facilitated the return to selected spots in the section. The resolution of the montage was adequate for counting the number of myelinated fibers. Structures that clearly were, or were suspected to be, unmyelinated fibers were photographed at higher magnification. The unmyelinated axons were counted in these detail micrographs. Table 2 lists the 3 strains from which 2 nerves to the $\mathrm{C} 2$ follicle were analyzed and the strain from which 3 nerves innervating $C^{\prime}$ follicles were analyzed.

In presenting all the results obtained with both the light and the electron microscope, we have made no distinction between the left and right sides or between sexes, as it was demonstrated that there was no correlation between these factors and our data.

\section{Results}

\section{Axon counts}

In Figure 3, data are presented for each strain, as means and SDs of the numbers of myelinated axons per follicular nerve. For each strain, the mean of all these means is displayed as a 
NUMBER OF PERI PHERAL AXONS

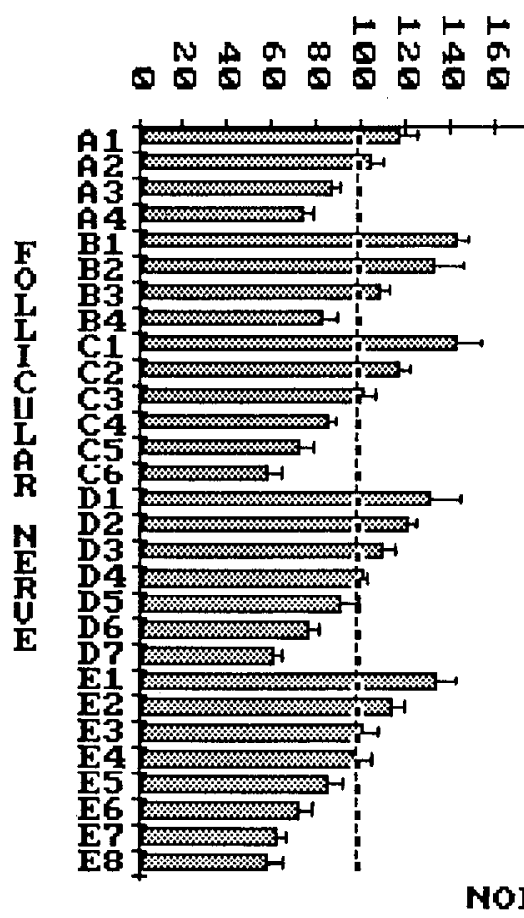

MOR

No o 0 क

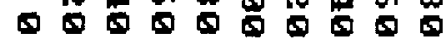



ถ



A $/ \mathbf{A}$

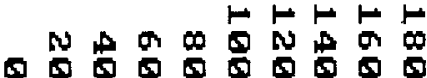

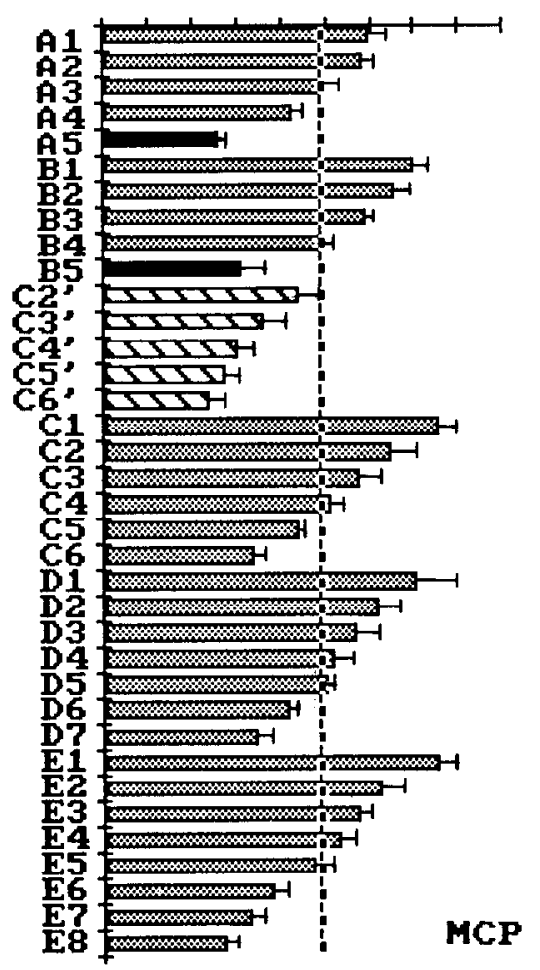


ถ

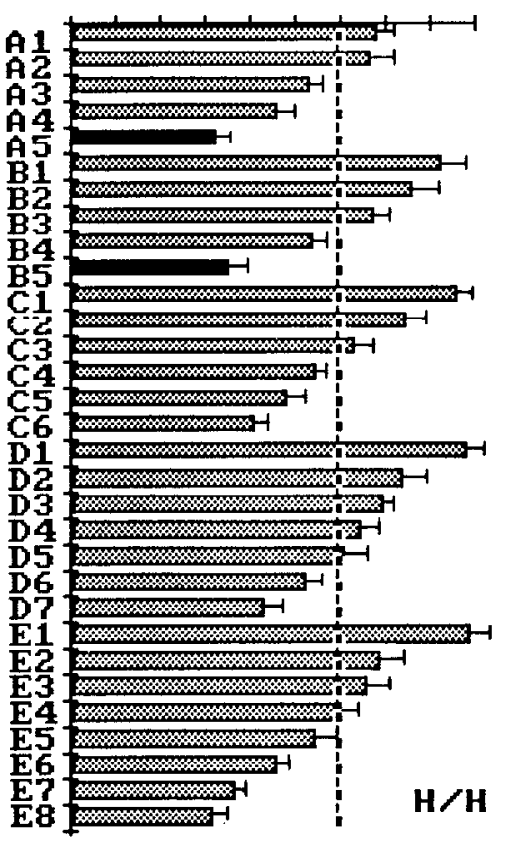

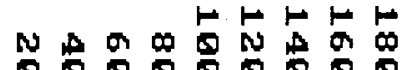



Figure 3. Counts of myelinated axons (horizontal axes) in nerves innervating individual vibrissal follicles (vertical axes) in the 6 strains of mice (names in right lower corner of each diagram). Each bar represents the mean number of axons innervating a particular follicle in a given strain. Horizontal lines at the right extremities of the bars represent SDs (not given when number of follicles analyzed was 5 or less). Stippled bars represent the innervation of follicles of the standard set; black bars concern supernumerary follicles A5 and B5; and hatched bars the follicles in supernumerary rows $A^{\prime}$ and $C^{\prime}$. Vertical dashed lines represent the mean of the means. See Table 1 for number of whiskerpads analyzed for each strain. 
vertical dashed line. Interestingly, these values are about 100 , except for $A / A$ and $H / H$, where they are about 120 . The data for SWs indicate that their follicles are innervated by a smallerthan-average number of nerve fibers. Note that in all strains, and for all rows of follicles, the nerves innervating the caudal follicles contain more axons than those innervating the rostral ones, which gives the bar graphs of Figure 3 a "pipe organ" pattern. SWs are no exception, either at the rostral end of a "standard" row or when forming a row of their own.

\section{Barrel areas}

All data on the cortex derive from Nissl material, and no corrections are entered for the $\sim 30 \%$ shrinkage (Rice and Van der Loos, 1977) that accompanies embedding in celloidin. Another (minor) correction was not made: The cortex containing the barrel assembly is slightly domed in the caudorostral direction and even more so in the mediolateral direction. Two to 6 tangential sections (usually 3 ) yielded a complete barrel field, ready for planimetry (drawing the lateral outline of $\mathrm{A}^{\prime}$ barrels created the only occasional difficulties).

For each strain, the means of the areas of the individual barrels and their SDs are presented in Figure 4. For the $N O R, A / A$, and $H / H$ strains, the mean of the means (vertical lines) lies around $3.5 \times 100 \mu \mathrm{m}^{2}$, while for the other strains these values are considerably lower. The caudal barrels are larger tangentially than the rostral ones. In general-taking into account their positions along the caudorostral axis - the SBs are smaller than the barrels of standard sets. As a group, the $\mathrm{A}^{\prime}$ barrels are the smallest.

\section{Ratios}

The area of each barrel was divided by the number of axons innervating the corresponding follicle. From the resulting ratios, means were calculated for each follicle-whisker pair and are shown in Figure 5; vertical lines represent the mean of the mean ratios for each strain. In general, the pipe organ pattern for each row of standard elements is reversed relative to the distribution of nerve fiber numbers or barrel sizes: The most rostral folliclebarrel pairs have a higher ratio than the more caudal pairs. This pattern is less obvious for the rows adjacent to rows of SEs and for those with an SE at their rostral end. The variations are due to differences in both barrel size and axon number.

\section{Global counts, measurements, and ratios}

For each strain, the mean total values for number of axons and size of the barrel field were calculated; the results appear in Figure 6, $a$ and $b$. Data pertaining to the SEs were kept separate from those of the standard set. The variation in the number of axons innervating all follicles together is not exactly paralleled by the variation in the size of the total barrel field. All "enriched" strains have different ratios (cortical area per peripheral axon) for SEs and elements of the standard set (Fig. $6 c$ ). In all cases, the $t$ test gave $p<0.03$.

\section{Representation of $S W S$}

The supernumerary follicles are represented by barrels located at topologically equivalent sites in the barrel field (Fig. 1). However, this rule does not hold in all cases. Among the 300 SWs analyzed in this study, 6 are not represented by a barrel. The follicular nerve (38 nerve fibers) shown in Figure $7 a$ innervates the only $B^{\prime}$ follicle observed. There is no barrel present at the corresponding site in the barrel field. There is, at this cortical site, an enlarged septum. In contrast, we never observed a barrel without a corresponding follicle.

Figure $7, b$ and $c$, illustrates the normally observed relationship between axon number and barrel area. In Figure $7 d$, at the site of the B2 follicle, there are 2 whiskers. Analysis of serial sections containing this exceptional follicle (in a plane above the section illustrated in Fig. $7 d$ ) showed both vibrissae to be well innervated (total number of axons, 184), while in the barrel field no separation of the extraordinarily large B2 barrel was observed.

Figure $8 a$ presents a case in which several barrels of the $C^{\prime}$ row are not situated at sites topologically equivalent to those of the corresponding follicles. In the barrel field, the more rostral barrels fill in the normally vacant area between the representations of the rhinal vibrissal follicles (Yamakado and Yohro, 1979) and the rostral elements of the $B$ and $C$ rows. Figure $8 b$ illustrates a case of perfect homeomorphism of the $\mathrm{C}^{\prime}$ elements.

Individual barrels may vary in shape because of the presence of SBs. In Figure 8, $c$ and $d$, the triangular shape of a B4 barrel is shown to become rectangular in response to the presence of a B5 barrel, which now exhibits the triangular form.

\section{Cortical thickness}

In Figure 9, the results of measurements of cortical thickness are presented as means of values obtained at 8 defined sites (Fig. 2) for each strain. The thickncsses of layers I, II and III, IV, and $V$ and VI are represented separately. The thickness of layer $I$ is virtually constant within 1 strain and between strains; that of layer IV, somewhat less so. In contrast, layers II and III and $\mathrm{V}$ and VI show an increase in thickness not only from caudal to rostral, but from medial to lateral. This holds for all strains, although in different proportions. Compare, for example, the results for strain $M A P$ with those of $M C P$ and $H / H: M A P$ has the thickest infragranular layers, and $M C P$ has the thinnest. $H / H$ shows the thickest supragranular layers (II and III).

\section{Electron-microscopic analysis}

In Table 2, the results of the counts of myelinated fibers and unmyelinated fibers are given. The data for the nerves innervating the $\mathrm{C} 2$ follicle show a remarkable correspondence between the number of myelinated fibers in the electron micrographs and the counts from the light-microscopic material. The number of nerve fibers in 1 of the 3 follicular nerves innervating an SW studied falls outside the range determined in the light microscope. Unmyelinated fibers in the follicular nerves form a minority that shows a high degree of variability, both within strains (see values for $M / M$ ) and between strains (compare values for $A / A$ with those for $M / M$ ). Figure 10 shows both classes of fibers and 2 examples of unmyelinated fibers in different relationships with their Schwann cells. The Schwann cell in Figure $10 \mathrm{c}$ does not envelop most of its unmyelinated fibers but rather shows the morphology of young oligodendrocytes with tongues extending to the axons. This arrangement was rarely found, and then only in the nerves of the $M / M$ animals.

\section{Discussion}

The establishment of strains of mice with different numbers and configurations of supernumerary follicles and barrels (Van der Loos et al., 1986) permits new approaches to the study of pattern formation and the genes that code for it.

\section{Sensory innervation of the vibrissal follicles and its variation between strains}

Our data are derived from a light-microscopic analysis of follicular nerves. The total number of myelinated fibers innervating the standard follicles of the whiskerpads of mice from different strains is, surprisingly, higher for the strains with SWs than for the one without them. To this already high number must be added the fibers destined for the SWs, in order to arrive at the total innervation for a whiskerpad of a given pattern.

Two questions come to mind: Is there a correlation between the total innervation of the standard follicles and the number of SWs on the whiskerpad of a mouse belonging to an "enriched" 
AREA $\times$ (19DUM) 2

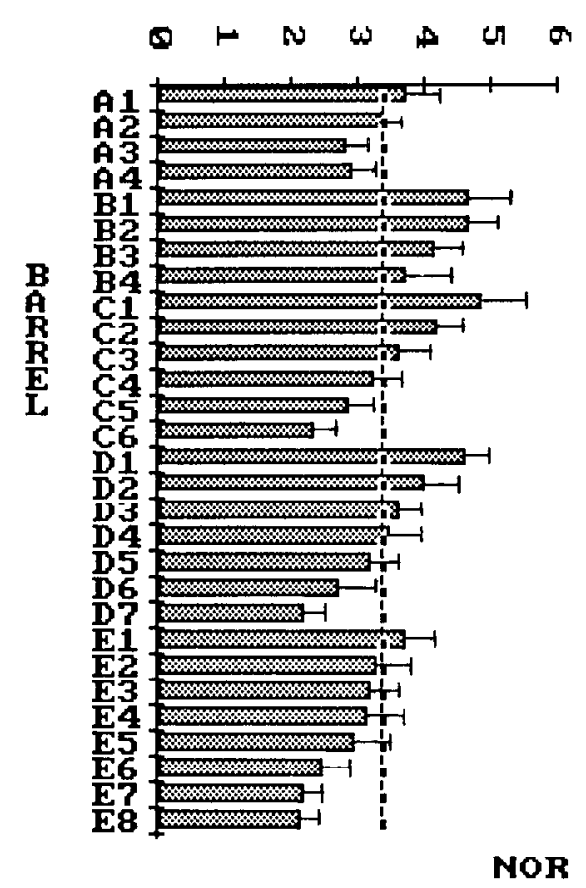

$\Delta \mapsto \omega \omega \pi$ \%

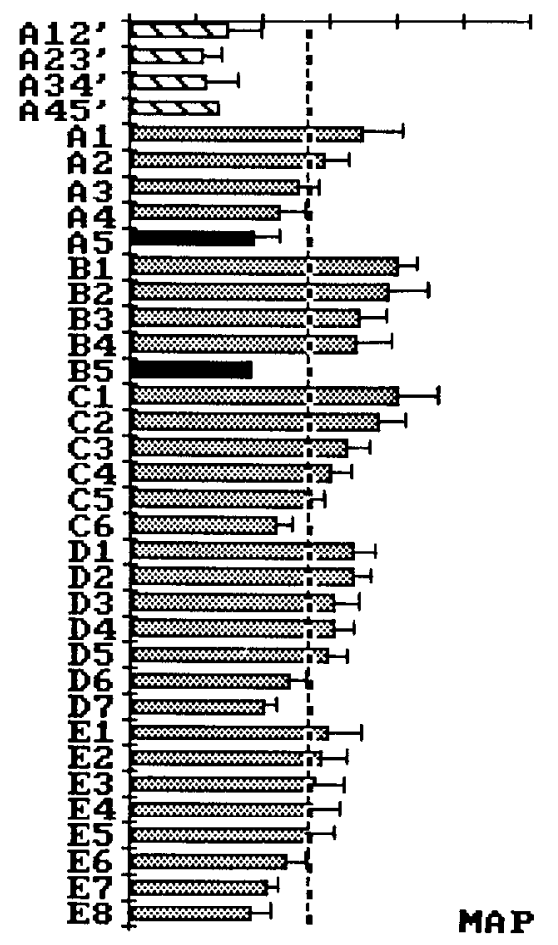

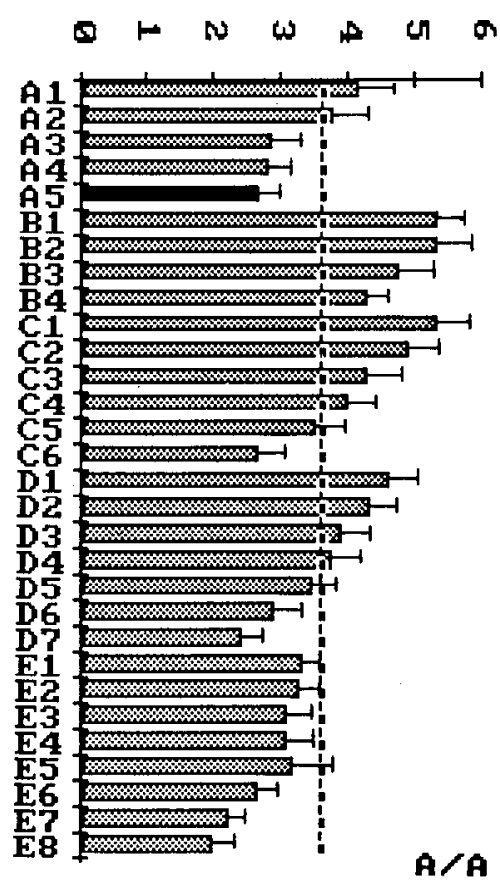
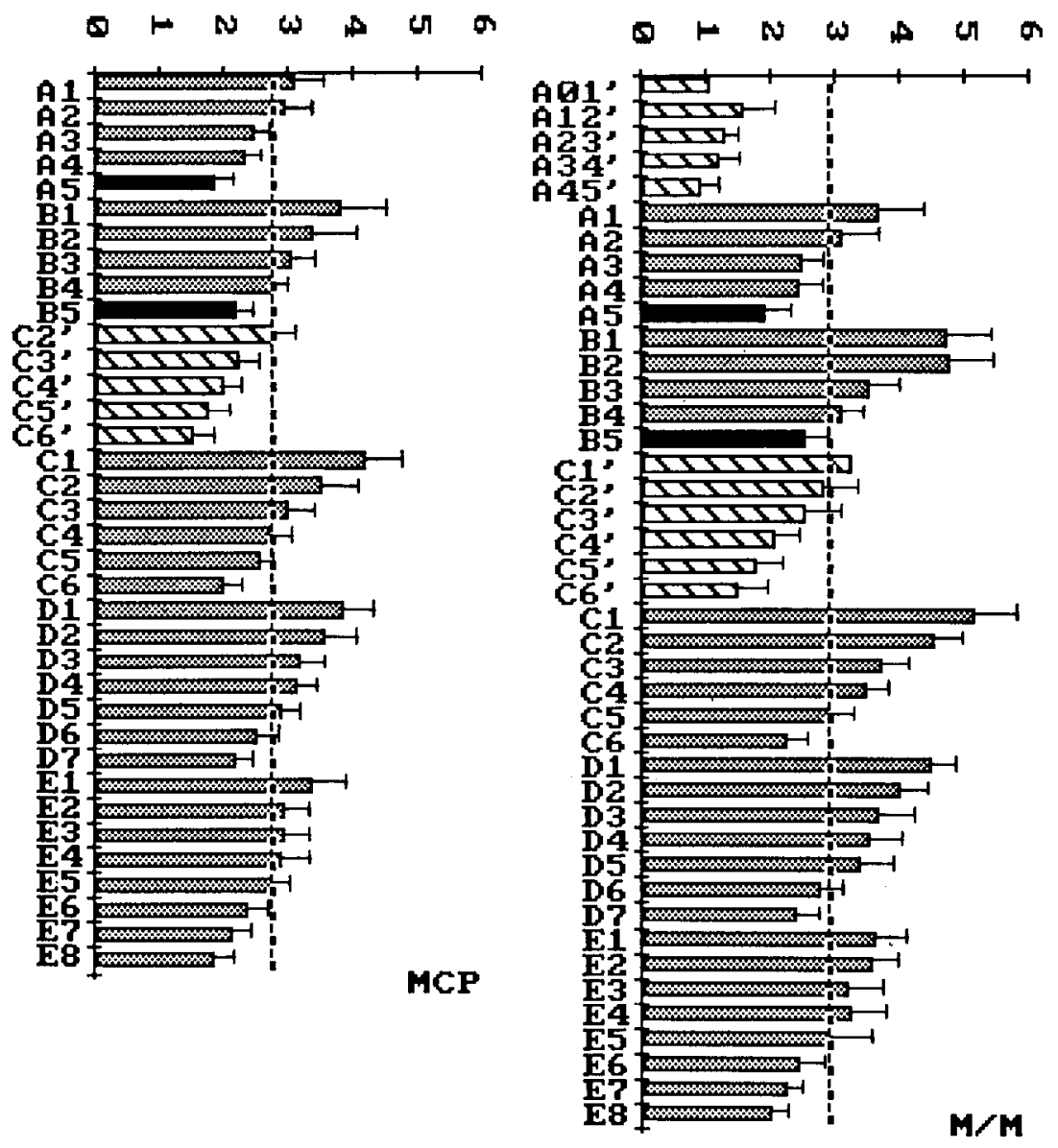

Figure 4. Area measurements (horizontal axes) of individual barrels (vertical axes) corresponding to mystacial vibrissae in the 6 strains of mice (names are in right lower corner of each diagram). Each bar represents the mean value of the area of a particular barrel in a particular strain. Horizontal lines at the right extremities of the bars represent SDs (not given when number of barrels measured was 5 or less). Stippled bars represent area of the barrels of the standard set; black bars concern supernumerary barrels A5 and B5; and hatched bars, barrels in supernumerary rows A' and $C^{\prime}$. Vertical dashed lines represent the mean of the means. See Table 1 for number of hemispheres analyzed for each strain. 
NOR

\begin{tabular}{|c|c|c|}
\hline & (1) & (2) \\
\hline & 3.69 & 116.6 \\
\hline & 3.32 & 104.3 \\
\hline & $\begin{array}{l}2.80 \\
2.88\end{array}$ & $\begin{array}{l}86.3 \\
73.2\end{array}$ \\
\hline & 4.65 & 142.3 \\
\hline & 4.63 & 132.3 \\
\hline & 4.11 & 107.5 \\
\hline & 3.69 & 82.9 \\
\hline & 4.83 & 142.8 \\
\hline & 4.17 & 116.5 \\
\hline & 3.59 & 100.7 \\
\hline & $\begin{array}{l}3.24 \\
2.84\end{array}$ & $\begin{array}{l}84.5 \\
72.8\end{array}$ \\
\hline & 2.30 & $\begin{array}{l}12.0 \\
57.5\end{array}$ \\
\hline & 4.61 & 130.3 \\
\hline & 3.9 & 120.2 \\
\hline & 3.61 & 109.9 \\
\hline & $\begin{array}{l}3.47 \\
3.19\end{array}$ & $\begin{array}{r}100.7 \\
91\end{array}$ \\
\hline & 2.65 & 76.1 \\
\hline & 2.16 & 60.4 \\
\hline & 3.6 & 133.5 \\
\hline & $\begin{array}{l}3.25 \\
3.10\end{array}$ & 113.5 \\
\hline & 3.14 & 96.0 \\
\hline & 2.95 & 85.3 \\
\hline & $\begin{array}{l}2.46 \\
2.16\end{array}$ & $\begin{array}{l}72.3 \\
61.7\end{array}$ \\
\hline & 2.1 & $\mathrm{~b} / . \mathrm{I}$ \\
\hline
\end{tabular}

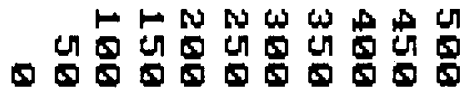

(3)
316.5
318.2
324.3
393.6
326.7
349.9
382.3
445.0
338.2
357.9
356.3
383.4
389.9
400.0
353.7
331.0
328.4
344.7
348.9
353.6
357.5
275.7
286.3
31.6
327.6
345.7
340.1
349.8
367.1

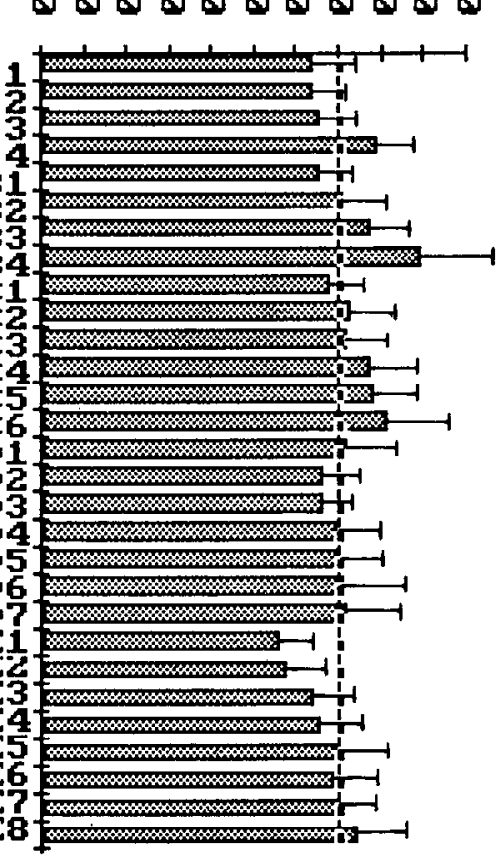

A $/ \mathbf{A}$

(1)

$\begin{array}{rr}4.14 & 131.9 \\ 3.73 & 127.5 \\ 2.83 & 100.0 \\ 2.77 & 93.8 \\ 2.64 & 62.2 \\ 5.31 & 173.1 \\ 5.33 & 157.9 \\ 4.73 & 132.2 \\ 4.26 & 105.3 \\ 5.30 & 178.0 \\ 4.89 & 152.5 \\ 4.25 & 131.7 \\ 3.97 & 110.7 \\ 3.51 & 94.1 \\ 2.65 & 72.5 \\ 4.58 & 164.2 \\ 4.32 & 148.4 \\ 3.87 & 127.4 \\ 3.73 & 118.9 \\ 3.48 & 105.2 \\ 2.90 & 83.7 \\ 2.39 & 70.2 \\ 3.32 & 158.6 \\ 3.28 & 139.8 \\ 3.07 & 124.9 \\ 3.07 & 110.6 \\ 3.19 & 98.0 \\ 2.65 & 78.5 \\ 2.21 & 63.8 \\ 1.98 & 57.4\end{array}$

(3)

\section{ค

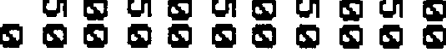

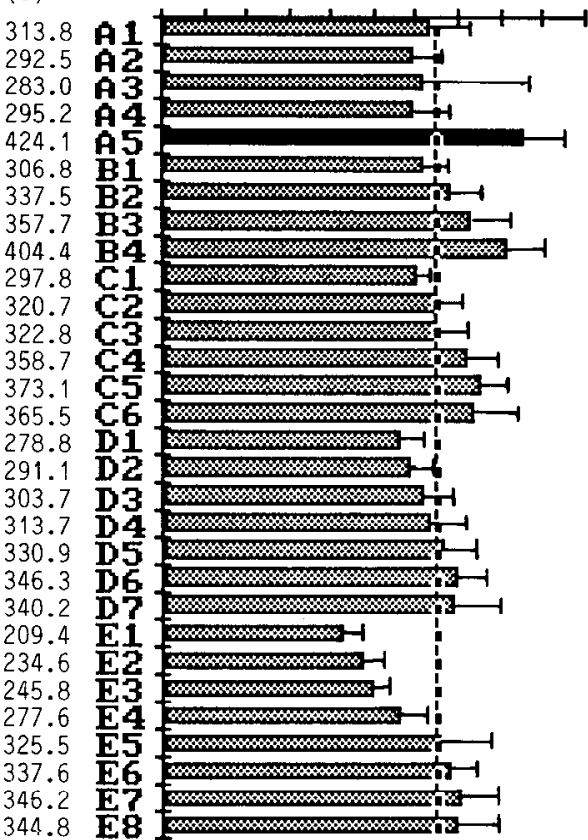

\begin{tabular}{lrl}
$\mathbf{H} / \mathbf{H}$ & & \\
& & \\
$(1)$ & \multicolumn{1}{l}{$(2)$} & $(3)$ \\
4.61 & 135.8 & 339.4 \\
4.11 & 133.7 & 307.5 \\
3.13 & 105.8 & 295.8 \\
2.66 & 92.2 & 288.6 \\
2.51 & 64.5 & 389.1 \\
4.78 & 164.8 & 290.0 \\
4.78 & 152.1 & 314.3 \\
4.11 & 133.8 & 307.1 \\
3.30 & 107.1 & 308.2 \\
3.00 & 70.0 & 428.6 \\
4.72 & 171.9 & 274.5 \\
4.21 & 148.9 & 282.7 \\
3.68 & 126.6 & 290.7 \\
3.41 & 108.3 & 314.8 \\
3.12 & 96.2 & 324.4 \\
2.69 & 81.0 & 332.1 \\
4.37 & 175.2 & 249.4 \\
3.86 & 147.1 & 262.4 \\
3.37 & 138.1 & 244.1 \\
3.56 & 128.9 & 276.1 \\
3.48 & 121.2 & 287.2 \\
2.94 & 104.0 & 282.7 \\
2.43 & 85.7 & 283.5 \\
3.67 & 176.7 & 207.7 \\
3.19 & 137.2 & 232.6 \\
3.00 & 131.5 & 228.1 \\
3.37 & 120.7 & 279.3 \\
3.23 & 109.2 & 295.7 \\
2.69 & 91.9 & 292.6 \\
2.14 & 72.7 & 294.5 \\
1.97 & 63.4 & 310.6
\end{tabular}

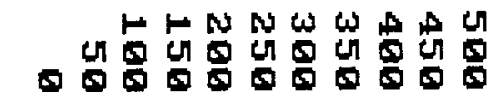

MAP



\section{(1) (2)}

$\begin{array}{ll}1.47 & 60.7 \\ 1.14 & 51.4\end{array}$

$1.12 \quad 44.8$

$1.32 \quad 36.0$

$3.50 \quad 127.2$

$2.90 \quad 119.4$

2.5196 .1

$2.25 \quad 86.8$

$\begin{array}{ll}1.86 & 55.2\end{array}$

$3.99 \quad 152.7$

$3.87 \quad 147.4$

$3.45 \quad 133.7$

$3.36 \quad 112.7$

$\begin{array}{ll}1.83 & 44.8\end{array}$

$3.98 \quad 165.7$

$3.72 \quad 142.0$

$3.24 \quad 123.8$

$3.01 \quad 107.7$

$\begin{array}{ll}2.70 & 90.7\end{array}$

$2.17 \quad 69.3$

$3.35 \quad 160.2$

$3.32 \quad 140.5$

$3.04 \quad 128.2$

$3.01 \quad 123.1$

$2.94 \quad 105.8$

$2.37 \quad 86.4$

$2.00 \quad 67.1$

$2.94 \quad 163.8$

$2.84 \quad 141.9$

$2.78 \quad 128.9$

$2.72 \quad 111.6$

$2.68 \quad 100.2$

2.32

1.82
(3)

242.2

222.0

250.1

366.7

275.2

242.8

261.2

259.1

337.1

262.5

258.1

298.2

408.5

240.

262.0

261.6

279.6
297.5

313.0

209.0

236.3
237.2

244.6

277.8

274.2

298.2

179.5

200.1

215.6

243.8

285.5

290.7

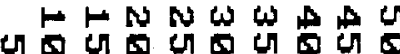
0606000000



Figure 5. Combination of tables and diagrams representing mean values of 3 parameters in the 6 mouse strains whose names are given above each table. The tables list data in 3 columns for individual elements (follicular nerves and barrels) named in column left of diagram. In the tables, column (1) gives the mean barrel areas in units of $100 \mu \mathrm{m}^{2}$; column (2), mean axon numbers; column (3), mean quotients (in $\mu \mathrm{m}^{2}$ ) of barrel area over axon number in the corresponding follicular nerve. In the diagrams, bars display graphically the values listed in column (3) of the tables. Horizontal lines at the right extremities of the bars represent SDs (not given when number of follicles analyzed was 5 or less). Vertical, interrupted lines indicate the mean of the mean quotients. Stippled bars represent the values of the standard set; black bars, those for the supernumerary elements A5 and B5; and hatched bars, elements in rows $\mathrm{A}^{\prime}$ and $\mathrm{C}^{\prime}$. See Table $\mathrm{I}$ for number of whiskerpads and barrel fields analyzed for each strain. 


\begin{tabular}{rrl} 
MCP & & \\
& & \\
1 & \multicolumn{1}{r}{$(2)$} & $(3)$ \\
3.10 & 119.7 & 259.1 \\
2.97 & 117.1 & 253.7 \\
2.48 & 98.8 & 250.9 \\
2.34 & 85.2 & 274.5 \\
1.85 & 51.6 & 358.7 \\
3.82 & 139.1 & 274.7 \\
3.41 & 130.5 & 261.3 \\
3.07 & 118.1 & 260.0 \\
2.73 & 99.1 & 275.5 \\
2.18 & 61.8 & 352.6 \\
2.75 & 87.2 & 315.4 \\
2.25 & 72.7 & 309.5 \\
2.00 & 61.2 & 326.8 \\
1.79 & 55.1 & 324.7 \\
1.52 & 47.7 & 318.9 \\
4.19 & 151.2 & 277.2 \\
3.56 & 129.6 & 274.7 \\
3.01 & 115.4 & 260.8 \\
2.73 & 101.4 & 269.2 \\
2.56 & 87.2 & 293.7 \\
2.01 & 67.2 & 299.2 \\
3.88 & 141.2 & 274.7 \\
3.56 & 123.7 & 287.7 \\
3.20 & 114.1 & 280.5 \\
3.14 & 104.1 & 301.7 \\
2.93 & 100.2 & 292.5 \\
2.55 & 83.4 & 305.7 \\
2.19 & 59.8 & 313.6 \\
3.39 & 150.2 & 225.6 \\
2.98 & 124.7 & 239.0 \\
2.96 & 114.8 & 257.8 \\
2.91 & 105.9 & 274.7 \\
2.75 & 94.9 & 289.7 \\
2.41 & 76.1 & 316.8 \\
2.14 & 65.8 & 325.1 \\
1.88 & 55.0 & 341.8 \\
& &
\end{tabular}



Figure 5. Continued.

\begin{tabular}{|c|c|c|}
\hline \multicolumn{3}{|c|}{$M / M$} \\
\hline (i) & (?) & (3) \\
\hline 10 & 71.0 & 147.9 \\
\hline & & \\
\hline & 50 & 52.0 \\
\hline & 49. & 39.0 \\
\hline 91 & 34 & 62.5 \\
\hline & 127. & 89.8 \\
\hline 11 & 114. & 272.0 \\
\hline & 94.5 & 264.4 \\
\hline 44 & 78. & 310.4 \\
\hline & 56 & 339.9 \\
\hline 74 & 153 & 310.1 \\
\hline 7 & 155 & 306.1 \\
\hline 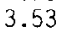 & 135 & 260.0 \\
\hline 3.12 & 109 & 85.2 \\
\hline F & & 34.0 \\
\hline 32 & 126 & 257.1 \\
\hline & 77 & 366.2 \\
\hline 5 & $6 \varepsilon$ & 364.4 \\
\hline & 63 & 327.2 \\
\hline 7 & 54 & 320.8 \\
\hline & 51. & 284.7 \\
\hline 1 & 161 & \\
\hline & 147 & 304.8 \\
\hline 3.7 & 138 & \\
\hline & 121. & 285.4 \\
\hline & & \\
\hline & & 302.4 \\
\hline & 150 & \\
\hline & 139 & 285.8 \\
\hline & & \\
\hline & 117 & 301.8 \\
\hline & 108 & \\
\hline & & 286.5 \\
\hline & & 314.3 \\
\hline & 157 & \\
\hline & 137 & \\
\hline & 124 & \\
\hline & 113 & \\
\hline & 100 & \\
\hline & 79 & \\
\hline & & \\
\hline & נc & \\
\hline
\end{tabular}



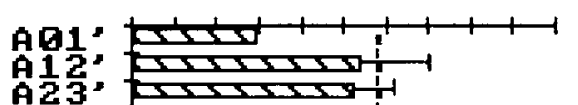

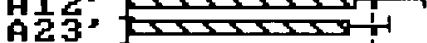

A34, 02001

45, Dowisis

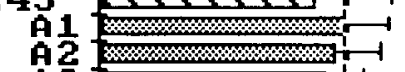

คิ



$\mathbf{B} \mathbf{4}$


c5

C6

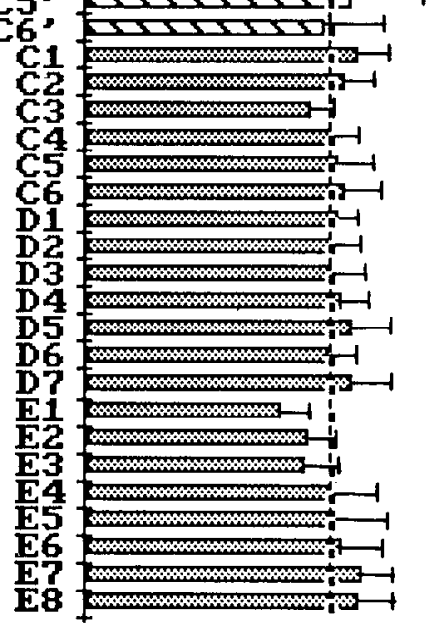

strain? Between strains, this appears not to be the case; the standard set of $A / A$ contains most fibers. We also tested this point within 1 strain, $M / M$, by grouping animals in 2 sets as divergent as possible with respect to number of SWs; no statistically significant difference between the 2 groups could be demonstrated. We conclude that the innervation of the standard follicles is not correlated with the number of SWs, which argues against the influence of a trophic substance secreted by follicle anlagen which would regulate the outgrowth of nerve fibers in a concentration-dependent fashion.

The second question is whether this tendency toward "overinnervation" is restricted to the trigeminal system or to a part of it, or whether it may be the expression of a general phenomenon.

The interstrain differences in innervation of the whiskerpad may be based on variations in (1) production of Gasserian neurons; (2) the naturally occurring death of the Gasserian neurons; (3) collateralization of trigeminal nerve fibers; (4) myelination (unmyelinated fibers could have acquired a myelin sheath and thus have become part of the group of axons that were counted in the light-microscopic analysis; see below); and (5) distribution of these nerve fibers over the 3 main branches of the trigeminal nerve, in favor of the infraorbital nerve.

The relationship between Gasserian ganglion cells and whiskerpads was recently studied in vitro by Lumsden and Davies
(1983), who concluded that the preferential outgrowth of fibers to the whiskerpad was caused by a trophic factor different from NGF and specific to the peripheral target.

In 3 strains there were extra rows with their own complement of fibers. We wondered whether fibers going to these extra rows were "borrowed" from the neighboring standard rows, or whether a global redistribution had taken place. The latter appears to have been the case: Considering the distribution of fibers over the standard rows only, the relative distribution for all 6 strains is about equal, regardless of the total number of fibers (Fig. 11).

Turning to the analysis of the innervation of individual follicles, we first note that, within rows, the more caudal, larger follicles are more heavily innervated; the variations in the counts per follicle in a particular strain are remarkably small. This holds for all strains and all rows, including rows containing, or consisting of, SWs.

The gradients of follicle innervation over the whiskerpads (Fig. 12) correlate well with the gradient by which the whiskerpad develops during embryogenesis: The first follicles appear at the "delta corner," the last at the rostral ends of rows A and B (Andrés and Van der Loos, 1983; Van der Loos et al., 1986; Van Exan and Hardy, 1980; Wrenn and Wessells, 1984). This correlation, although not counterintuitive, is not easy to explain.

The electron-microscopic analysis of 9 follicular nerves showed the presence of unmyelinated fibers, also noted by Lee and 
TOTAL PERI PHERAL AXONS

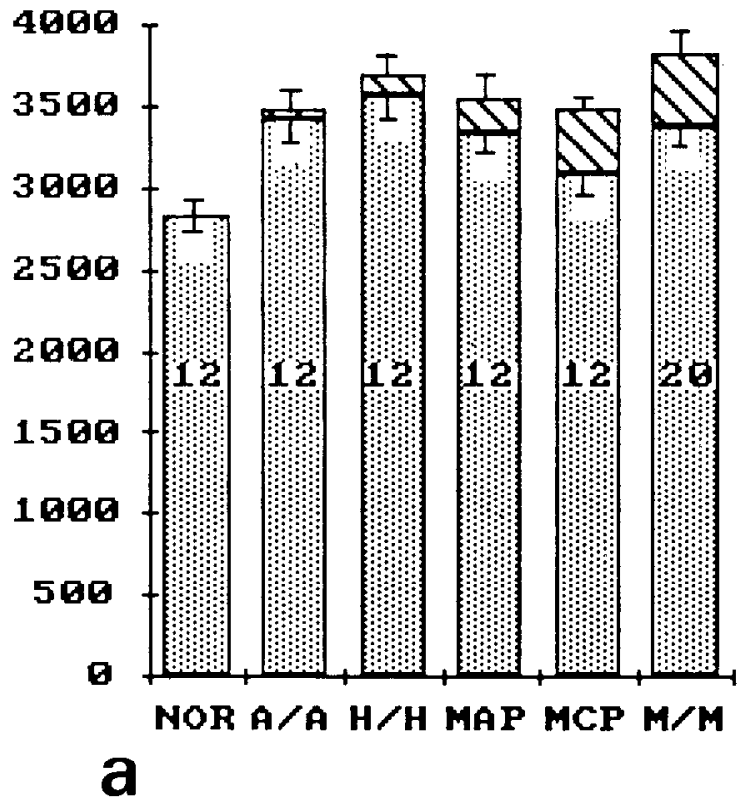

BARRELF I ELD AREAS

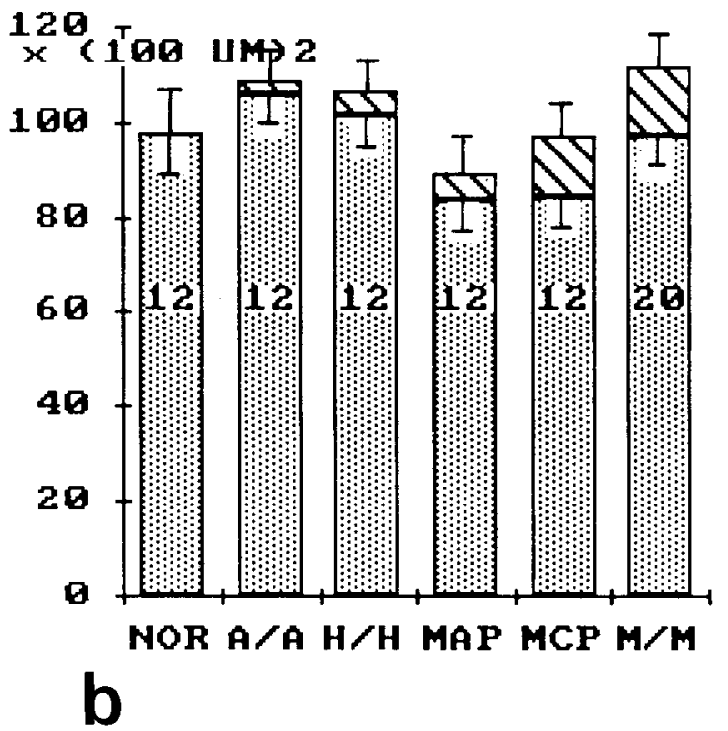

AREA PER PERI PHERAL AXON

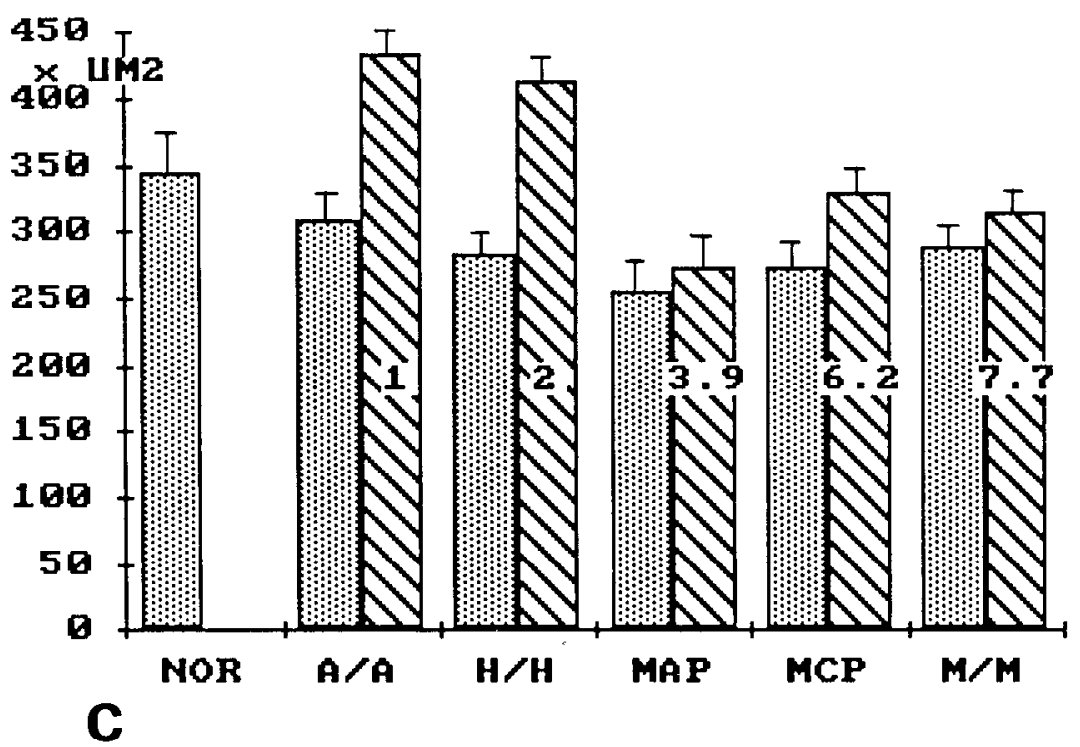

Figure 6. Global values of the 3 parameters analyzed for each of the 6 strains listed along the abscissae of the bar graphs. $a$, Columns showing total number of nerve fibers innervating standard follicles (stippled parts) and supernumerary follicles (hatching). In each column, the 2 vertical lines represent SDs: The downward-directed line concerns the standard set of follicles; the upward-directed line concerns total innervation (standard plus supernumeraries). The numbers within the columns give the number of whiskerpads analyzed per strain. $b$, Mean areas of the barrel field. Stippled parts of columns represent mean total areas of standard barrels; hatching, the area of the extra barrels. For other conventions, see legend for $a$. $c$. Mean quotients - barrel-field area divided by total number of nerve fibers innervating the corresponding part of the whiskerpad-of the 2 components of the pathway. Stippled parts represent standard elements; hatching, supernumerary elements. Numbers inside hatched columns give mean number of extra elements. Lines above columns represent SDs. For other conventions, see legend for $a$.

Woolsey (1975). They were half as numerous as myelinated axons in NOR, but only between one-fifth and one-seventh as numerous as in $A / A$. The greater number of myelinated axons in $A / A$ may be due to the myelination of fibers that were unmyelinated in NOR. In the strains investigated, the number of myelinated fibers was well within the range found with the light microscope, except for 1 of the 3 nerves innervating $C^{\prime}$ s in $M C P$, possibly an exceptional case.

Two explanations for the configuration of the oligodendroglialike Schwann cells present themselves. Elfvin (1962) demonstrated that the positions of unmyelinated fibers with respect to Schwann cells vary, owing to differences in osmolarity of the 

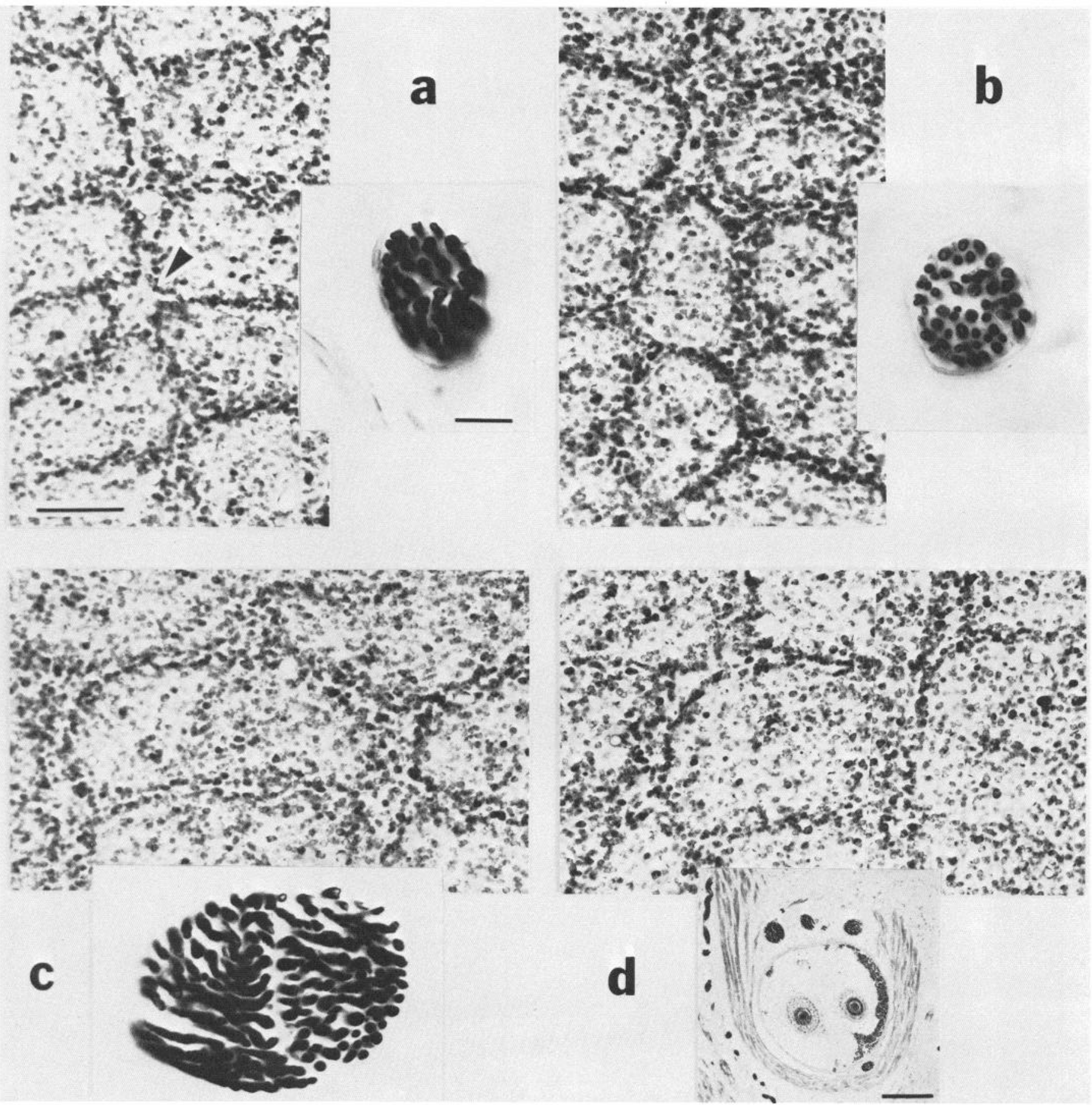

Figure 7. Relationships between whiskerpad and barrel field as demonstrated in 4 sets of photomicrographs of follicular nerves and their corresponding cortical representations. Photomicrographs of barrels are taken from Nissl-stained sections cut tangentially to the cortical surface; all have the same magnification (bar in $a, 100 \mu \mathrm{m}$ ). Photomicrographs of follicular nerves are taken from myelin-stained sections cut tangentially to the whiskerpad surface and show in $a, b$, and $c$ the resolution of analysis; they have the same magnification (bar in $a, 20 \mu \mathrm{m}$ ). The bivibrissal follicle in $d$ receives its innervation from 4 branches of the infraorbital nerve, 1 reaching the follicle from rostral (bar: $300 \mu \mathrm{m}$ ). In $a$, no barrel is visible at the site (arrowhead) corresponding to that of the follicle innervated by the nerve shown in insert. At this cortical site, the septum formed by the 5 adjacent barrels of the B row (to the right) and the A row (to the left) is large. The nerve is small: it has 38 myelinated fibers. $b$, Small $\mathrm{C}^{\prime}$ barrel (center) is shown between the B row (to the left) and C row (to the right), together with the nerve that innervates the corresponding follicle. Barrel and nerve (53 fibers) were among the smallest we observed. $c$, One of the largest barrels (B1, center) is shown, together with the innervation (184 fibers) of the corresponding follicle. The photomicrograph in $d$ shows 2 vibrissae together in 1 follicle (B2), which is surrounded by a single muscle sling. The corresponding barrel (center) is indeed large but is not subdivided. 

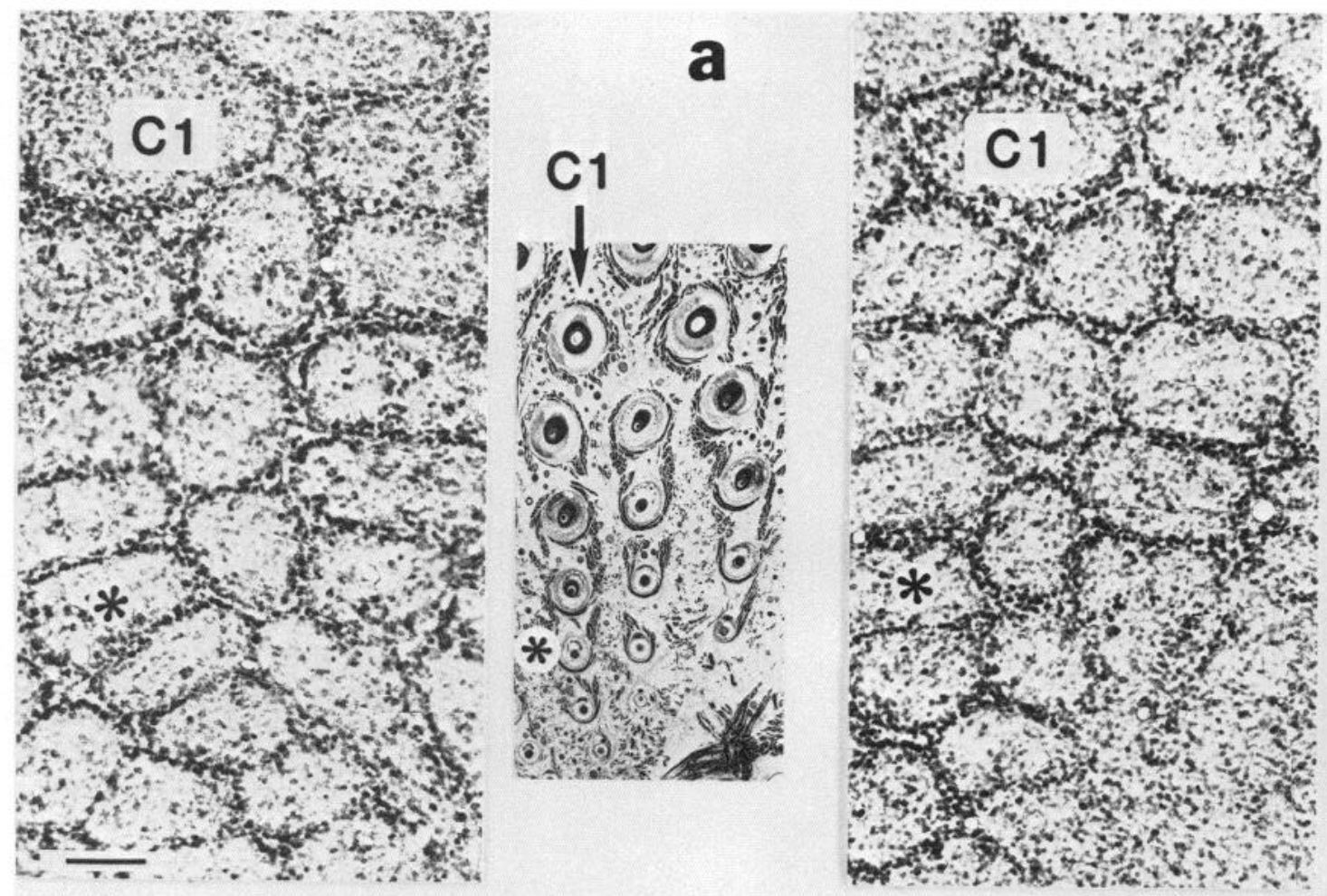
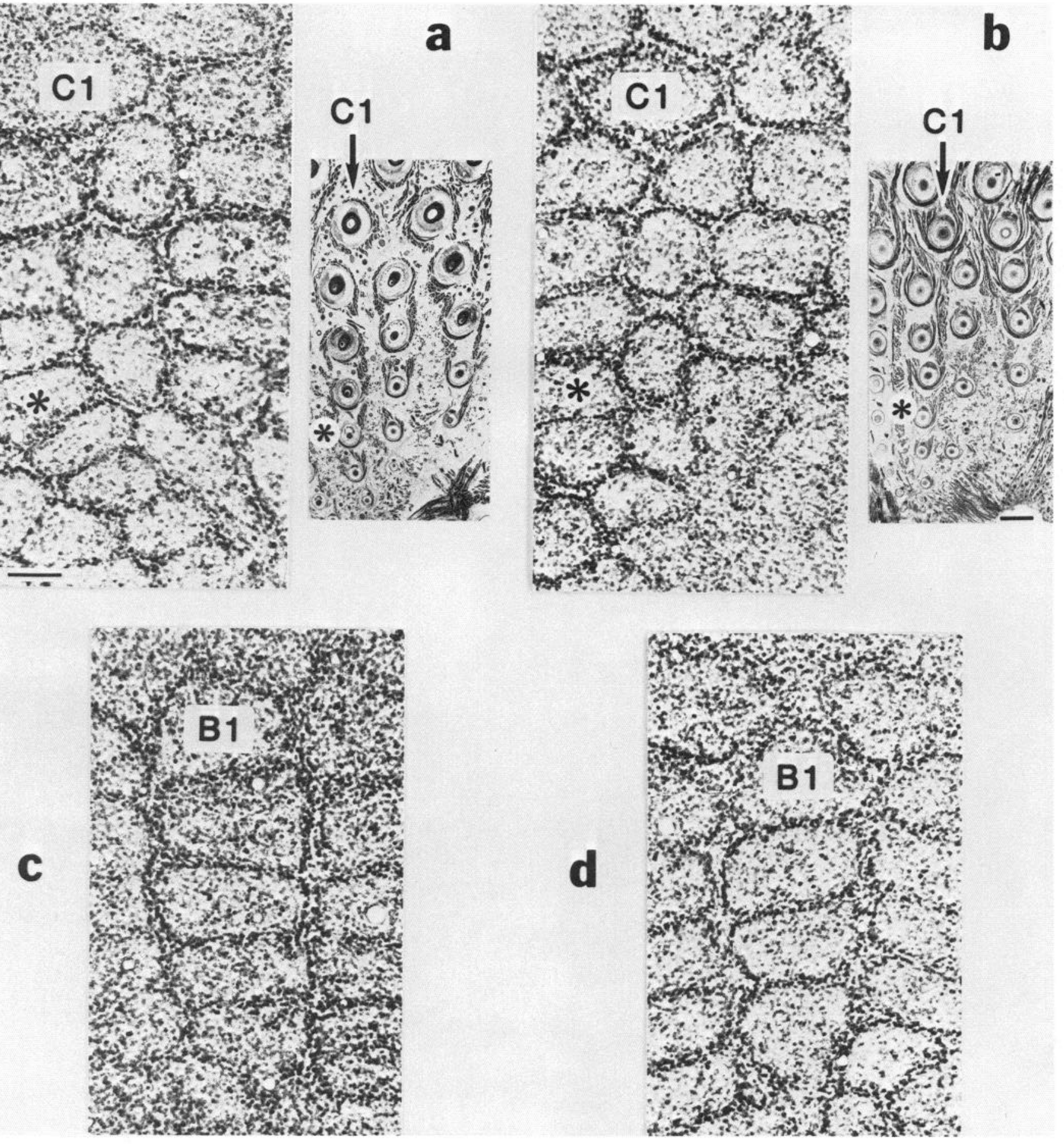

Figure 8. Photomicrographs giving evidence that factors act upon barrel formation in the CNS which are probably not of peripheral origin. $a$, The topology of the central representation of the whiskers of a $\mathrm{C}^{\prime}$ row (vertical row, center) does not correspond to the situation in the periphery: The $\mathrm{C}^{\prime}$ follicle is represented by a barrel at the $\mathrm{C} 6$ and 7 position. The $\mathrm{Cl}$ and $\mathrm{C} 5$ (asterisk) elements are marked. $b$, Perfect homeomorphic correspondence between whiskers of the $\mathrm{C}^{\prime}$ row and their corresponding barrels (vertical row, center). Same elements marked as in $a$. The orientations of barrel fields and whiskerpads in $a$ and $b$ are chosen to facilitate the comparison of patterns. Photomicrographs $c$ and $d$ show a B row (vertical) and demonstrate the differences in shape of a B4 barrel: in $c$, it is roughly rectangular, whereas B5 is "triangular" in form, i.e., similar to the B4 in $d$. The 4 photomicrographs of parts of barrel fields are at the same magnification (bar in $a, 100 \mu \mathrm{m}$ ). They are from Nissl-stained sections cut tangentially to the pia. The pictures of the whiskerpads are from sections cut tangentially to the epidermis and stained by a reduced-silver method. They are at the same magnification (bar in $b$ placed in nostril, $0.5 \mathrm{~mm}$ ). 



\section{I}

Figure 9. Thickness measurements made in the barrel cortex of 36 coronally cut hemispheres of mice from the 6 strains analyzed (names at bottom right corner of each diagram). For each strain, mean values are given for measurements made at 2 points $(M$ and $L)$ in each of 4 sections analyzed per hemisphere (see Fig. 2). The labels $M 1, M 2, L 1$, etc., displayed above the horizontal axes, correspond to points $M$ and $L$ in the 4 sections; e.g., $M 3$ corresponds to point $M$ in section 3 . The thickness is plotted vertically, 1 bar representing the mean total thickness for a particular measuring point (SD for total cortical thickness is indicated by line at lower end of bar). Subdivisions of bars correspond to mean thickness of layers (key at bottom). SD of the mean value of layer IV is given at the lower end of layer IV. 

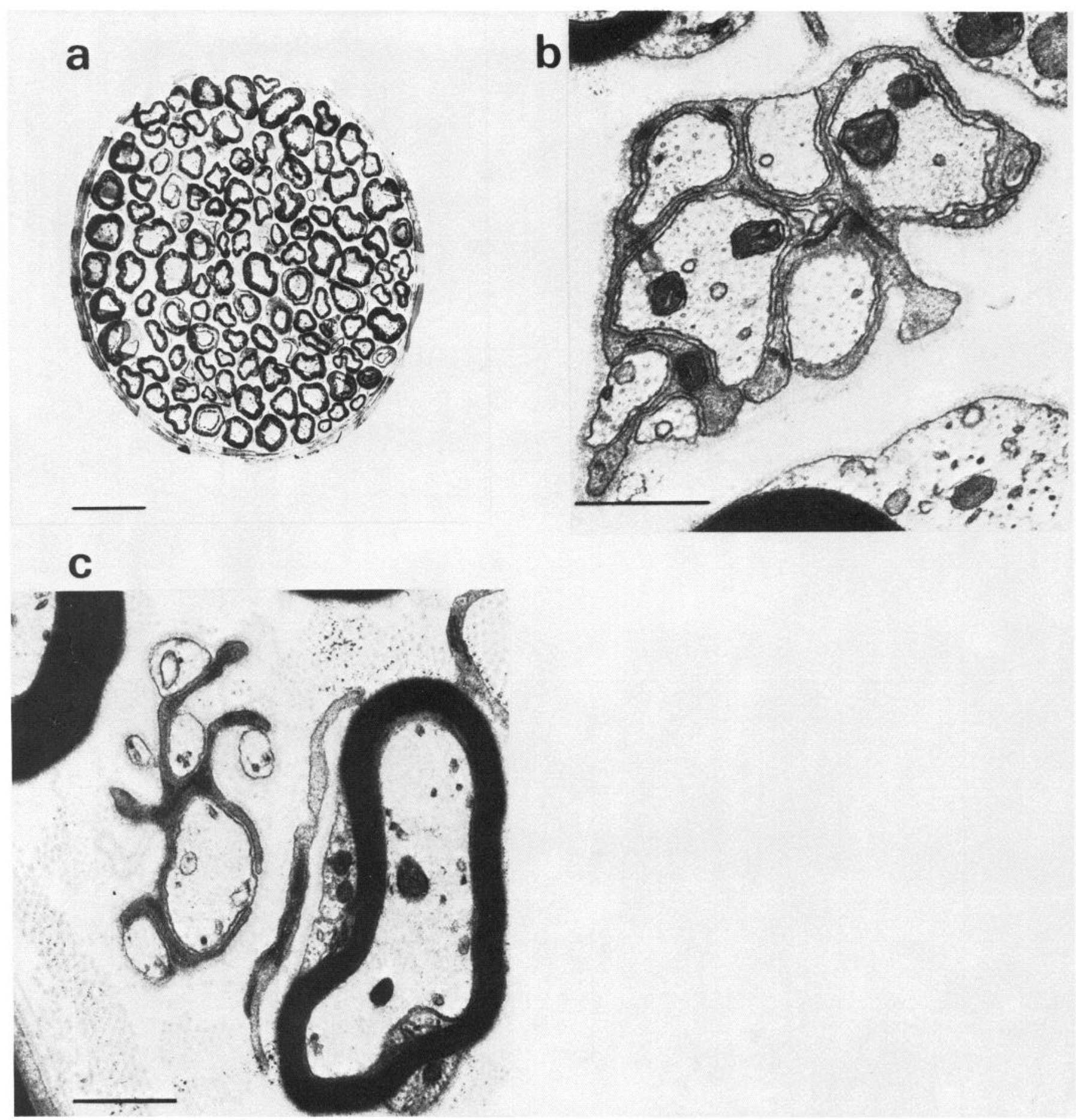

Figure 10. Photomicrographs of the electron-microscopic analysis. $a$, Greatly reduced picture of montage of 62 electron micrographs through the $\mathrm{C} 2$ follicular nerve of a NOR mouse (bar, $10 \mu \mathrm{m})$. b. Schwann cell enveloping 7 unmyelinated axons. $c$, Schwann cell having an unusual "oligodendroglia-like" relationship with 5 of its 6 unmyelinated axons. Bars in $b$ and $c, 0.5 \mu \mathrm{m}$.

perfusion fluid. However, in our material, most other groups of such fibers were enveloped normally by their Schwann cells. Alternatively, the Schwann cell was just at the point of "releasing its axons," to be captured by new Schwann cells that were ready to myelinate.

\section{Measurements of barrels and barrel fields and their variations} between strains

The total area of the barrel field varies little within strains, but greatly between them. $M / M$ had the largest total area: $21 \%$ larger than that of $M A P$, the strain with the smallest barrel field. Together, the standard barrels of $A / A$ have the largest area: $25 \%$ larger than that of $M C P$, the strain with the smallest such area. The standard area is not a simple function of the number of $\mathrm{SBs}$, whereas the total area of SBs is related almost linearly to their number: $A / A$ has the smallest, and $M / M$ the largest, area. Does a larger-sized barrel field imply colonization of neighboring cortical areas, or does it result in an overall increase of the neocortical surface?

The most caudal barrels in a row were the largest. In all strains 

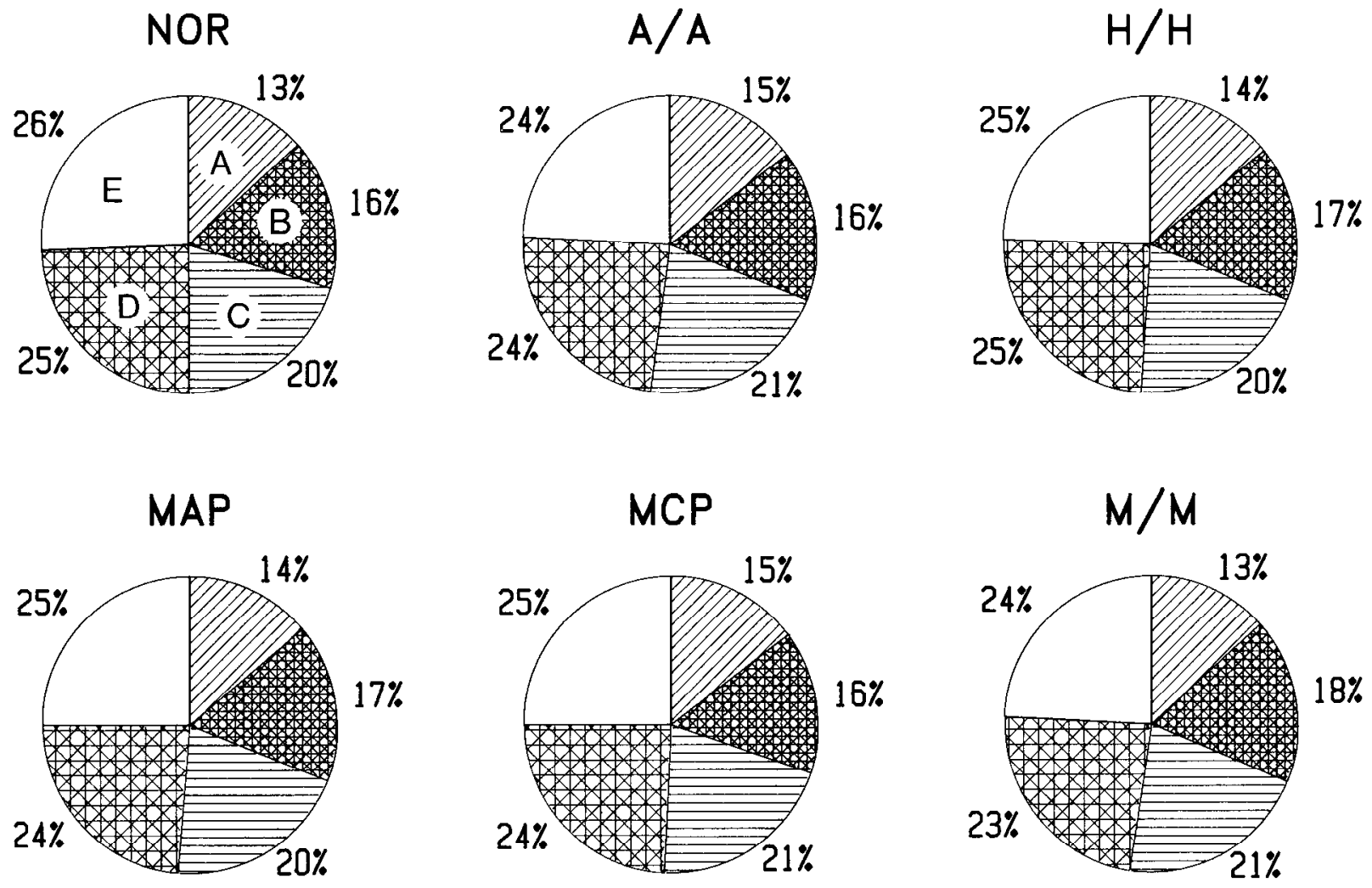

Figure 11. Comparison of the relative distributions of nerve fibers over the standard rows of whisker follicles (A, B, C, D, and E) on the whiskerpads of the 6 strains analyzed. Pie graphs show, for each strain, the percentage of fibers per row, including, when present, follicles A5 and B5. Supernumerary rows $\mathrm{A}^{\prime}$ and $\mathrm{C}^{\prime}$ are not included.

and all rows, with very few exceptions, there was a size gradient: the more rostral the barrel, the smaller its area. A similar gradient was also observed by T. A. Woolsey and Wann (1976).

The fact that $\mathrm{C}^{\prime}$ barrels are not always located at sites that correspond with "their" whiskers (compare Fig. 8, $a$ and $b$ ) suggests that the pallium prefers to express the representation of a newly acquired sensory organ in an "improper" place than not to represent it at all. The shape of the $B 5$ barrel and the variation in shape of the B4 barrel (compare Fig. 8, $c$ and $d$ ) reflects the fact that, in different strains, barrels are equally closely packed.

The total thickness of the barrel cortex is not constant: For all strains, it increases from posteromedial to anterolateral. Similar to the gradient of follicle innervation, this gradient of thickness corresponds to the sequence in which the whiskerpad develops: The thinnest cortex is at the "delta corner," the part of the barrel field to develop last, as inferred from the fact that the wave of corticogenesis in the parietal region travels from lateral to medial (Smart and McSherry, 1982) and from rostral to caudal (Smart, 1983).

Interestingly, layers I and IV, input layers of the barrel cortex, appear to have a constant thickness over the entire barrel field, and variations between strains are small. Larger variations occur in layers II and III and V and VI, which are primarily output layers (for connectivity of the barrel cortex, see Wise, 1975, and White and DeAmicis, 1977). It is these variations that account for those in the total cortical thickness within the barrel field of a given strain, as well as for the interstrain differences in cortical thickness. The constancy in thickness of layers I and IV argues against the influence of the curvature of the cortex on these measurements. Rose (1929), in his classic atlas of the mouse cortex, illustrates Lorente de Nó's (1922) “glomérulos" (barrels), together with the gradients in (partial) cortical thickness within the same area.

We observe, comparing strains, that the constancy in radial extent of layer IV is in marked contrast to the variation we noted in areal extent, which seems to point to the existence of different developmental rules for the establishment of radial and

Table 2. Results of electron-microscopic analysis of peripheral nerves

\begin{tabular}{|c|c|c|c|c|c|}
\hline \multirow[b]{2}{*}{ Strain } & \multirow{2}{*}{$\begin{array}{l}\text { Genera- } \\
\text { tion }\end{array}$} & \multirow[b]{2}{*}{ Whisker } & \multicolumn{2}{|c|}{ No. of myelinated axons } & \multirow{2}{*}{$\begin{array}{l}\text { No. of } \\
\text { unmy- } \\
\text { elinated } \\
\text { axons } \\
\text { (EM) }\end{array}$} \\
\hline & & & EM & Lillie & \\
\hline NOR & 25 & $\mathrm{C} 2$ & 111 & $(107-126)$ & 53 \\
\hline NOR & 25 & $\mathrm{C} 2$ & 133 & & 54 \\
\hline$A / A$ & 19 & $\mathrm{C} 2$ & 156 & $(144-163)$ & 33 \\
\hline$A / A$ & 19 & $\mathrm{C} 2$ & 142 & & 21 \\
\hline$M / M$ & 12 & $\mathrm{C} 2$ & 149 & $(133-161)$ & 66 \\
\hline$M / M$ & 12 & $\mathrm{C} 2$ & 153 & & 124 \\
\hline$M C P$ & 20 & $\mathrm{C}^{\prime}$ & 116 & $(35-94)$ & 43 \\
\hline$M C P$ & 20 & $\mathrm{C}^{\prime}$ & 96 & & 31 \\
\hline$M C P$ & 20 & $\mathrm{C}^{\prime}$ & 74 & & 30 \\
\hline
\end{tabular}

The axon counts wcre made in the montages of clcctron micrographs of 6 follicular nerves innervating the $\mathrm{C} 2$ follicles in 3 different strains and in 3 montages of nerves innervating $C^{\prime}$ follicles (see Fig. 10). Data for myelinated and unmyelinated fibers are presented separately. For a comparison of the data from this analysis with those based on counts in the light-microscopic material, ranges of the latter are added in parentheses. 

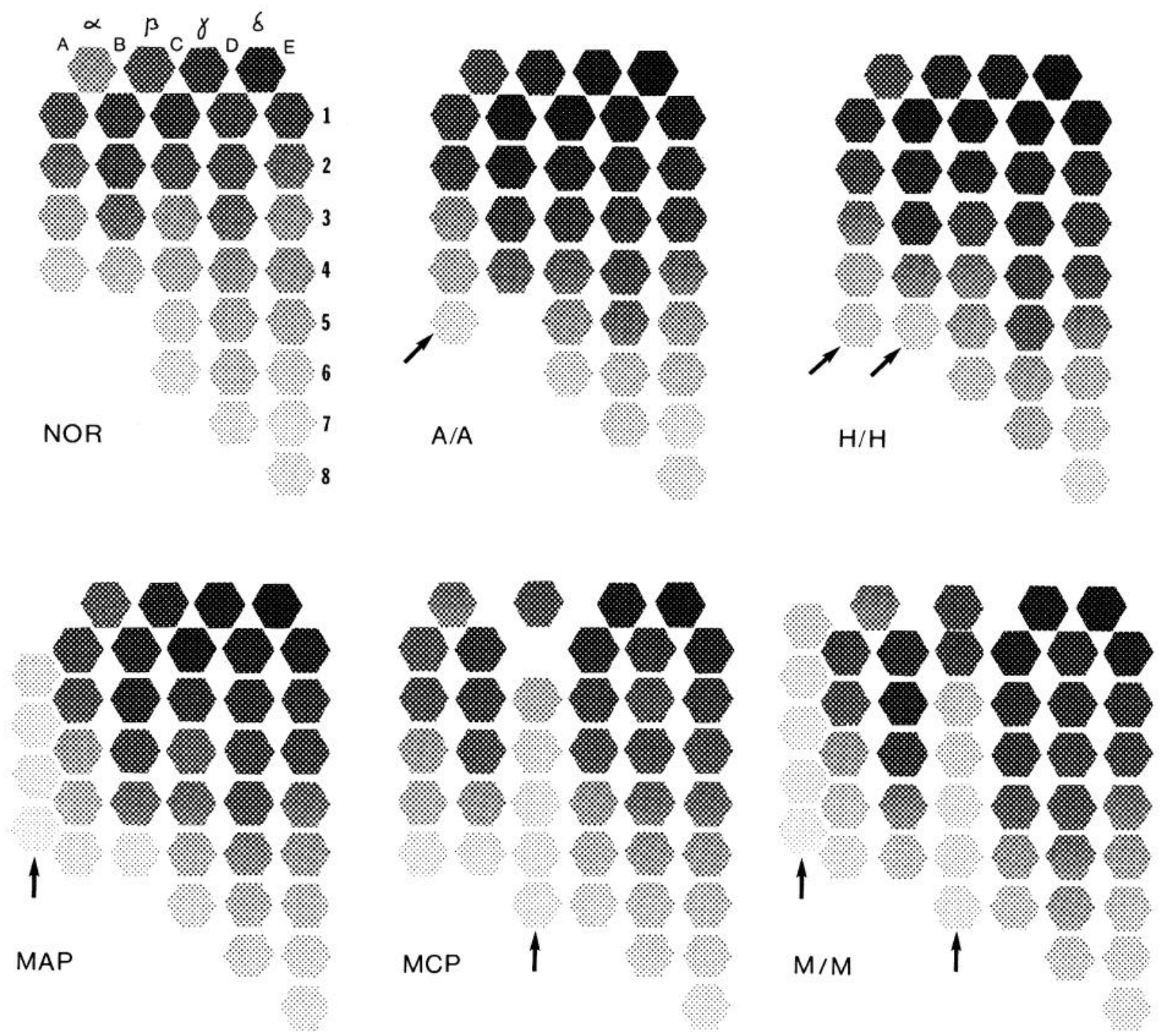

Figure 12. Impressionistic rendition of innervation density of the follicles of the whiskerpad for the 6 strains (names at bottom of each graph). The hexagons symbolize follicles (letters and numbers in NOR denote conventional terminology); their gray level, the mean number of nerve fibers that innervate them [see, for numerical values, column (3) of tables in Fig. 5]. Note that straddling elements $\alpha, \beta, \gamma$, and $\delta$ (top rows of hexagons) have been added, although they do not figure among the results presented in the text. Arrows indicate the supernumerary follicles for which animals were selectively bred.

tangential dimensions for a given layer of cortex. Caviness et al. (1976) and Rice et al. (1985) came to similar conclusions concerning radial and tangential organization on the basis of different observations that, incidentally, were also made in the barrel field.

\section{Relationship between areas of cortical barrels and innervation of vibrissal follicles}

The mean ratio of the standard set of elements is different for all 6 strains studied. In all cases, the mean ratio for the SEs is higher than that for the standard set of the same strain. Elsewhere, we have speculated that this may be a factor in the evolution of the brain: A focal addition to an assembly of receptors may be treated preferentially by the cortex, particularly in that its representation increases (Welker and Van der Loos, 1986).

As one moves rostrally along a row of whiskers, the cortical space per follicular nerve fiber increases: The smaller elements of the standard rows have a greater cortical area per peripheral axon than the larger ones. Taking cortical thickness measurements into account, the difference between caudal and rostral elements becomes even more dramatic: In terms of "barrel columns" (a column being a barrel plus the cortical tissue above and below it), the smaller, rostral columns appear to have more cortical volume per peripheral nerve fiber than the larger, caudal ones. Physiological experiments (Nussbaumer and Van der Loos, 1985) have demonstrated that the rostral barrels receive input not only from the vibrissal follicles but also from the skin between them, while the caudal barrels receive signals only from whiskers. Thus, the rostral barrels may be in need of more volume because of the dual nature of their thalamic input, one input being from the skin, whose sensory innervation did not enter into our analysis.

We have tried to estimate the number of cortical neurons per peripheral axon. Both Van Erp Taalman Kip (1938; for a summary, see Bok and Van Erp Taalman Kip, 1939) and Rockel et al. (1980) determined the number of neurons under 10,000 $\mu \mathrm{m}^{2}$ of pial surface over the parietal cortex of mice to be about 1500 . We calculated the mean area of barrel cortex per axon for the NOR mouse to be $343.9 \mu \mathrm{m}^{2}$, which amounts to $(343.9 / 10,000) \times 1500=\sim 50-60$ cells/peripheral axon. This, in turn, appears to be compatible with the results of Lee and 

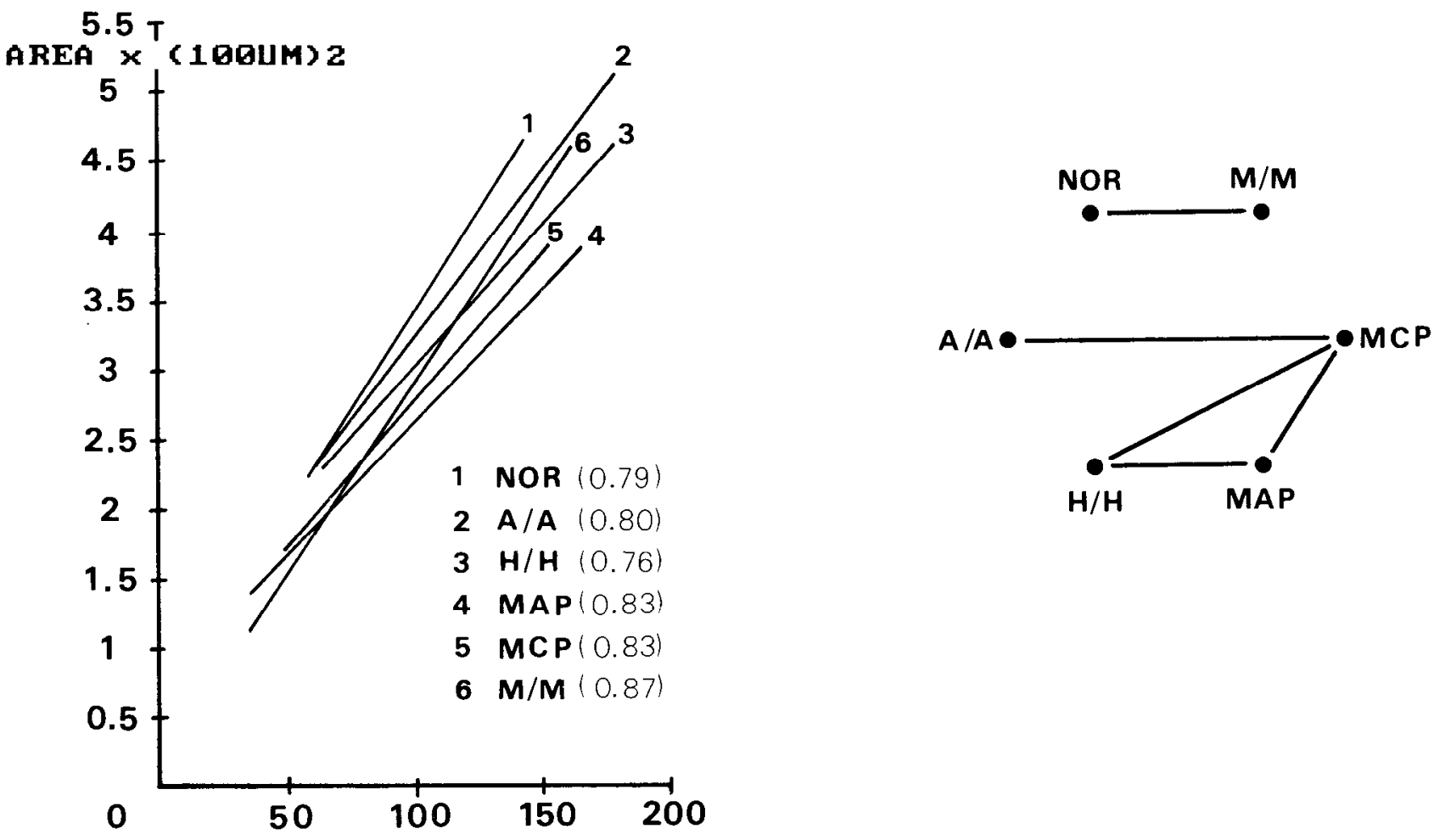

\section{PERI PHERAL AXONS}

Figure 13. Results of regression analyses performed for each strain on the number of axons in follicular nerves and the tangential area of the corresponding barrels. Left, For each strain, all data points (each defined by the number of axons in a follicular nerve and the area of the corresponding barrel) were included in the analysis. It was found that, for all strains, the correlation of both parameters was highly significant $(p<0.001)$. The origin of the graph $(0,0)$ is included within the confidence band of $95 \%$ of each line. Therefore, we conclude that a directly proportional relationship exists between the number of peripheral axons and the area of cortical representation. The number above each line indicates a strain, as listed in the insert together with the correlation coefficient. Right, The slope of each line was tested against that of every other line using an analysis of covariance; the result is displayed in graphic form. Where 2 strains are connected, the slopes of their regression lines are not different $(p>0.05)$.

Woolsey (1975): After pooling their cell counts from 6 barrels $(11,629)$ and the total fiber counts from the 6 corresponding whiskers (683), one arrives at a count of 17 cells/axon in layer IV. It seems reasonable that one-third of the barrel-field neurons are in layer IV. It would be interesting to compare these values between strains: Would some strains compensate for their small barrel area with an increased cell density?

The relationship between peripheral innervation and central representation can be studied in another way, ignoring the neighborhood relationships of the elements in question. Figure 13 gives the results of a regression analysis incorporating all folliclebarrel pairs, grouped by strain. The regression lines indicate that within each strain there is a directly proportional relationship between the number of peripheral axons and the areal extent of the corresponding individual barrels. The slopes of the lines express the "cortical magnification factors" for the various strains. Ten of the 15 pairs of strains showed statistically significant differences in slope. Thus, it appears that strains of mice bred for different whisker patterns and separated from one another for about 20 generations "choose" different ways to establish harmony between an important part of their somatosensory periphery and its cortical representation. In their detailed mapping study of the macaque primary visual cortex, Dow et al. (1985) mention interindividual and interhemispheric differences in magnification factor in the foveal representation. (Daniel and Whitteridge, 1961, defined this factor as millimeters of visual cortex measured tangentially to its surface and corresponding to $1^{\circ}$ of visual field.)

When biological variations are observed, it is of general in- terest to determine their limits. The minimal number of nerve fibers per follicular nerve analyzed was 22 ( $\mathrm{A}^{\prime}$ in an $M / M$ animal); the maximum, 196 ( $\mathrm{C} 1$ in an $A / A$ animal). The smallest and largest barrels measured had areas of $0.34 \times 100 \mu \mathrm{m}^{2}\left(\mathrm{~A}^{\prime}\right.$ in an $M / M$ animal) and $6.22 \times 100 \mu \mathrm{m}^{2}$ (a B2 barrel in $\left.A / A\right)$. For the ratios, the maximum value was 8.31 (B5 in $M A P$ ) and the minimum, $1.14\left(\mathrm{~A}^{\prime}\right.$ in $\left.M A P\right)$. The largest $\mathrm{B} 2$ barrel among the $M C P$ animals corresponded to a bivibrissal follicle (Fig. $7 b$ ). Evidently, the duplication of an element in the periphery was reflected in the cortex, in that the barrel size corresponded to the peripheral innervation. What signal emanating from the whiskerpad would be needed for the cortex to construct 2 barrels within a space that is apparently already allocated?

The smallest $\mathrm{C}^{\prime}$ barrel we found was substantially larger than the $\mathrm{C}^{\prime}$ barrels observed at the beginning of the breeding program, i.e., about 15 generations earlier (see Fig. 3a in Van der Loos and Dörfl, 1978): Selective breeding leads not only to more SWs but also to an increase in the size of their cortical representation (possibly associated with increased peripheral innervation).

Several statements have been made concerning the establishment of topological equivalency between the stations of the whisker-to-barrel pathway: (1) The pattern is first laid down in the periphery at the level of the incipient whiskerpad (Andrés and Van der Loos, 1983; Van der Loos, 1979; Van der Loos and Dörfl, 1978); (2) the pattern is transmitted to the nuclei of termination in the brain stem by a topologically ordered projection of the trigeminal nerve (Erzurumlu and Killackey, 1983); and (3) during postnatal maturation of the pathway, each central station instructs the next higher one, resulting in the deposition 
of a pattern (Durham and Woolsey, 1984; Killackey, 1980; Van der Loos, 1979; Van der Loos and Dörfl, 1978; for a recent review, see Van der Loos and Welker, 1985). The need to explain the formation of barrel patterns became stronger after it was proven that the pathway was able to express plasticity, i.e., the capability of its stations to adapt themselves in a "creative" manner to changes that had been experimentally inflicted within a critical period (e.g., Jeanmonod et al., 1981). These experiments-usually lesions of vibrissal follicles-lead to various changes in the entire pathway. Here, we tested the plasticity of the system by exposing it to peripheries that differed in vibrissal pattern. Our analysis was restricted to parameters that were determined at the first and the last station of the pathway. It is not yet clear where, between skin and barrel field, the cortical variations may be generated. We dare not speculate in general terms about the mechanisms by which the pathway reacts to the various peripheries. However, there is some consistency among all 6 strains. This is discussed in the following paragraphs.

In the establishment of the pattern in the CNS, the topological relationships of the periphery are preserved. In only a few cases did we observe deviations from this rule.

For a follicle to be represented by a barrel, it appears that a threshold number of nerve fibers is needed. The smallest number of axons in the nerve of a follicle with a barrel was 22 , while the largest number of axons in the nerve of a follicle without a barrel was 38 . The threshold is likely to vary with the position of the follicle on the whiskerpad. However, our material is too limited for any definitive statement.

In the establishment of whisker representation, spatial information about entire rows is transmitled differently from that about the pipelines within a row (Andrés and Van der Loos, 1985; Killackey and Belford, 1979). We propose that, before the "maplike" subdivision of the pathway occurs, rough homeomorphic connections between its stations already exist. This is in line with the observations of Killackey (1985), who issued the "caveat ... that neither the somatosensory cortex nor any other trigeminal processing station is a tabula rasa...." $\mathrm{He}$ based this statement on work showing rough topologic relations between periphery and brain stem, and between thalamus and cortex, before the follicle pattern is expressed and before the ventrobasal complex is parceled, respectively. In the same vein, it has been demonstrated that, in the congenital absence of an eye, a rough homeomorphic relationship exists between the central stations of the visual pathway of the mouse (Godemont et al., 1979; Kaiserman-Abramov et al., 1980; Rhoades et al., 1985).

The presence of extra whiskers has an effect on the barrel area-peripheral innervation ratio of neighboring elements (Fig. 5 ), and it seems that a minimal number of peripheral fibers is needed for a whisker follicle to be presented by a cortical unit. These observations may indicate that, during map formation, competition for space occurs. This competition may take place between the fibers of the Gasserian neurons within the nuclei of termination, for we did not find any indications of such competition between the peripheral fibers of these neurons: The total number of fibers innervating the standard follicles was distributed in the 6 strains according to the same "rules" (see Fig. 11). The relative size of the central representation is a function of the number of peripheral nerve fibers that innervate the corresponding follicle. The overall barrel-field size, orientation, and location, as well as the shape of the individual barrels, may well be determined by factors residing within the CNS.

We do not claim that our "standard" mice of the NOR strain are standard in the sense of providing a baseline for comparison. They do indeed possess the standard elements present in the other 5 strains, but they are as much the product of inbreeding as are the other strains.
The question arises as to whether the genes that code for the various follicle patterns are the ones responsible, either directly or indirectly, for the other strain differences that we report; or are the latter established by other genes? Our analysis cannot answer this question; cross-breeding between mice from different strains, interstrain transplantation of parietal cortex, and the creation of mosaic mice would be among the experiments needed to address this fundamental question.

\section{References}

Andrés, F. L., and H. Van der Loos (1983) Cultured embryonic noninnervated mouse muzzle is capable of generating a whisker pattern. Int. J. Dev. Neurosci. 1: 319-338.

Andrés, F. L., and H. Van der Loos (1985) From sensory periphery to cortex: The architecture of the barrelfield as modified by various early manipulations of the mouse whiskerpad. Anat. Embryol. 172: 11-20.

Andres, K. H. (1966) Über die Feinstruktur der Rezeptoren an Sinushaaren. Z. Zellforsch. 75: 339-365.

Bok, S. T., and M. J. Van Erp Taalman Kip (1939) The size of the body and the number of the nerve cells in the cerebral cortex. Acta Morphol. Neerl. 3: 1-22.

Caviness, V. S., Ir., D. O. Frost, and N. L. Hayes (1976) Barrels in somatosensory cortex of normal and reeler mutant mice. Neurosci. Lett. 3: 7-14.

Constantine-Paton, M., and M. I. Law (1978) Eye-specific termination bands in the tecta of three-eyed frogs. Science 202: 639-641.

Cruz, M. C., D. Jeanmonod, K. Meier, and H. Van der Loos (1984) A silver and gold technique for axon and axon-bundles in formalinfixed central and peripheral nervous tissue. J. Neurosci. Methods 10 : $1-8$.

Daniel, P. M., and D. Whitteridge (1961) The representation of the visual field in the cerebral cortex in monkeys. J. Physiol. (Lond.) 159: 203-221.

Dow, B. M., R. G. Vautin, and R. Bauer (1985) The mapping of visual space onto foveal striate cortex in the macaque monkey. J. Neurosci. 5: 890-902.

Durham, D., and T. A. Woolsey (1984) Effects of neonatal lesions on mouse central trigeminal pathways. J. Comp. Neurol. 223: 424-447.

Elfvin, L.-G. (1962) Electron microscopic studies on the effect of anisotonic solutions on the structure of unmyelinated splenic nerve fibers of the cat. J. Ultrastruct. Res. 7: 1-38.

Erzurumlu, R. S., and H. P. Killackey (1983) Development of order in the rat trigeminal system. J. Comp. Neurol. 213: 365-380.

Ghysen, A. (1980) The projection of sensory neurons in the central nervous system of Drosophila: Choice of the appropriate pathway. Dev. Biol. 78: 521-541.

Godemont, P., P. Saillour, and M. Imbert (1979) Thalamic afferents to the visual cortex in congenitally anophthalmic mice. Neurosci. Lett. 13: 271-278.

Hamburger, V. (1939) Motor and sensory hyperplasia following limbbud transplantation in chick embryos. Physiol. Zool. 12: 268-284.

Hollyday, M., and V. Hamburger (1976) Reduction of the naturally occurring neuron loss by enlargement of the periphery. J. Comp. Neurol. 170: 311-320.

Jeanmonod, D., F. L. Rice, and H. Van der Loos (1981) Mouse somatosensory cortex: Alterations in the barrelfield following receptor injury at different early postnatal ages. Neuroscience 6: 1503-1535.

Kaiserman-Abramov, I. R., A. M. Graybiel, and W. J. H. Nauta (1980) The thalamic projection to cortical area 17 in a congenitally anophthalmic mouse strain. Neuroscience 5: 41-52.

Killackey, H. P. (1980) Pattern formation in the trigeminal system of the rat. Trends Neurosci. 3: 303-306.

Killackey, H. P. (1985) Intrinsic order in the developing rat trigeminal system. In Development. Organization. and Processing in Somatosensory Pathways, M. Rowe and W. D. Willis, eds., pp. 43-51, Liss, New York.

Killackey, H. P., and G. R. Belford (1979) The formation of afferent patterns in the somatosensory cortex of the neonatal rat. J. Comp. Neurol. 183: 285-304.

Lee, K. J., and T. A. Woolsey (1975) A proportional relationship between peripheral innervation and cortical neuron number in the somatosensory system of the mouse. Brain Res. 99: 349-353. 
Lorente de Nó, R. (1922) La corteza cerebral del ratón. Trab. Lab. Invest. Biol. Univ. Madrid 20: 41-78.

Lumsden, A. G. S., and A. M. Davies (1983) Earliest sensory nerve fibers are guided to peripheral targets by attractants other than nerve growth factor. Nature 306: 786-788.

Melzer, P., H. Van der Loos, J. Dörfl, E. Welker, P. Robert, D. Emery, and J.-C. Berrini (1985) A magnetic device to stimulate selected whiskers of freely moving or restrained small rodents; its application in a deoxyglucose study. Brain Res. 348: 229-240.

Nussbaumer, J.-C., and H. Van der Loos (1985) An electrophysiological and anatomical study of projections to the mouse cortical barrelfield and its surroundings. J. Neurophysiol. 53: 686-698.

Rhoades, R. W., R. D. Mooney, and S. E. Fish (1985) Subcortical projections of area 17 in the anophthalmic mouse. Dev. Brain Res. 17: 171-181.

Rice, F. L., and D. Anders (1977) A small guillotine to prepare brains for sectioning in defined, odd planes. Neurosci. Lett. 6: 157-163.

Rice, F. L., and H. Van der Loos (1977) Development of the barrels and barrel field in the somatosensory cortex of the mouse. J. Comp. Neurol. 171: 545-560.

Rice, F. L., C. Gomez, C. Bartow, A. Burnet, and P. Sands (1985) A comparative analysis of the development of the primary somatosensory cortex: Interspecies similarities during barrel and laminar development. J. Comp. Neurol. 236: 447-495.

Rockel, A. J., R. W. Hiorns, and T. P. S. Powell (1980) The basic uniformity in structure of neocortex. Brain 103: 221-244.

Rose, M. (1929) Cytoarchitektonischer Atlas der Grosshirnrinde der Maus. J. Psychol. Neurol. 40: 1-51.

Smart, I. H. M. (1983) Threc dimensional growth of the mouse isocortex. J. Anat. 137: 638-694.

Smart, I. H. M., and G. M. McSherry (1982) Growth patterns in the lateral wall of the mouse telencephalon. II. Histological changes during and subsequent to the period of isocortex production. J. Anat. 134: 415-442.

Spurr, S. R. (1969) A low viscosity epoxy resin embedding medium for electron microscopy. J. Ultrastruct. Res. 26: 31-43.

Suga, N., and P. H.-S. Jen (1976) Disproportional tonotopic representation for processing species-specific CF-FM sonar signals in the mustache bat auditory cortex. Science 194: 542-544.

Suga, N., J. A. Simmons, and P. H.-S. Jen (1975) Peripheral specialization for fine analysis of Doppler-shifted echoes in "CF-FM" bat Pteronotus parellii. J. Exp. Biol. 63: 161-192.

Van der Loos, H. (1979) The development of topological equivalences in the brain. In Neural Growth and Differentiation, E. Meisami and M. A. B. Brazier, eds., pp. 331-336, Raven, New York.

Van der Loos, H., and J. Dörfl (1978) Does the skin tell the somatosensory cortex how to construct a map of the periphery? Neurosci. Lett. 7: 23-30.

Van der Loos, H., and E. Welker (1985) Development and plasticity of somatosensory brain maps. In Development, Organization, and Processing in Somatosensory Pathways, M. Rowe and W. D. Willis, Jr., eds., pp. 53-67, Liss, New York.

Van der Loos, H., J. Dörfl, and E. Welker (1984) Variations in pattern of mystacial vibrissae in mice; a quantitative study of ICR stock and several inbred strains. J. Hered. 75: 326-336.
Van der Loos, II., E. Welker, J. Dörfl, and G. Rumo (1986) Selective breeding for variations in patterns of mystacial vibrissae of mice; bilaterally symmetrical strains derived from ICR-stock. J. Hered. 77. 66-82.

Van Erp Taalman Kip, M. J. (1938) Lichaamsgrootte en hersenschors. Doctoral thesis, University of Leiden.

Van Exan, R. J., and M. Hardy (1980) A spatial relationship between innervation and the early differentiation of vibrissa follicles in the embryonic mouse. J. Anat. 131: 643-656.

Vincent, S. B. (1913) The tactile hair of the white rat. J. Comp. Neurol. 23: $1-36$

Welker, E., and H. Van der Loos (1983) Genetically determined supernumerary mystacial vibrissae in albino mice (ICR): Association with peripheral innervation and with size of barrelfield. Neurosci. Lett. (Suppl.) 14: S401.

Welker, E., and H. Van der Loos (1984a) Relationship between number of vibrissal follicles (VFs) and number of their myelinated sensory fibers (SFs); a study in three new strains of mice: NOR, MCP and $\mathrm{M} / \mathrm{M}$. Experientia 40: 652 .

Welker, E., and H. Van der Loos (1984b) The innervation of mystacial vibrissae in mice selectively bred for different whisker patterns. Neurosci. Lett. (Suppl.) 18: S176.

Welker, E., and H. Van der Loos (1986) Is areal extent in sensory cerebral cortex determined by peripheral innervation density? Exp. Brain Res. 63: 650-654.

Welker, E., P. Melzer, J. Dörfl, and H. Van der Loos (1985) The sensory effectiveness of supernumerary mystacial vibrissae (SWs) in the mouse; a deoxyglucose (DG) study of the barrelfield. Experientia 41: 1219 .

White, E. L., and R. A. DeAmicis (1977) Afferent and efferent projections of the region in mouse SmI cortex which contains the posteromedial barrel subfield. J. Comp. Neurol. 175: 455-482.

Wise, S. P. (1975) The laminar organization of certain afferent and efferent fiber systems in the rat somatosensory cortex. Brain Res. 90 : 139-142.

Woolsey, C. N., W. H. Marshall, and P. Bard (1942) Representation of cutaneous tactile sensibility in the cerebral cortex of the monkey as indicated by evoked potentials. Bull. Johns Hopkins Hosp. 70 399-441.

Woolsey, T. A., and H. Van der Loos (1970) The structural organization of layer IV in the somatosensory region (SI) of the mouse cerebral cortex: The description of a cortical field composed of discrete cytoarchitcctonic units. Brain Rcs. 17: 205-242.

Woolsey, T. A., and J. R. Wann (1976) Areal changes in mouse cortical barrels following vibrissal damage at different postnatal ages. J. Comp. Neurol. 170: 53-66.

Wrenn, J. T., and N. K. Wessells (1984) The early development of mystacial vibrissae in the house mouse. J. Embryol. Exp. Morphol. 83: $137-156$.

Yamakado, M., and T. Yohro (1979) Subdivision of mouse vibrissae on an embryological basis, with descriptions of variations in the number and arrangement of sinus hairs and cortical barrels in BALB/c $(n u /+$; nude; $n u / n u)$ and hairless $(h r / h r)$ strains. Am. J. Anat. 155: $153-174$ 